Check for updates

Cite this: RSC Adv., 2022, 12, 2123

Received 8th October 2021 Accepted 6th January 2022

DOI: $10.1039 / \mathrm{d} 1 \mathrm{ra07470a}$

rsc.li/rsc-advances

\title{
Formation and selected catalytic properties of ruthenium, rhodium, osmium and iridium nanoparticles
}

\begin{abstract}
Jan Krajczewski, ${ }^{\text {*a }}$ Robert Ambroziak (DD ${ }^{\mathrm{b}}$ and Andrzej Kudelski (D) *a
The synthesis and applications of nanoparticles formed from various platinum-group metals have been intensively investigated for many years because such systems have many important commercial applications, mainly as heterogeneous catalysts. Because of the very large number of data concerning nanoparticles of the platinum-group metals, in this review we focus only on nanoparticles formed from less frequently used members of the platinum family (i.e.: ruthenium, rhodium, osmium and iridium). Various methods of synthesis of unsupported and supported nanoparticles from these elements are described. Some example applications of such systems as catalysts have been also described, mainly those, for which there is a clear dependence of the catalytic activity on the size and shape of used nanoparticles.
\end{abstract}

\section{Introduction}

The platinum-group metals (PGMs) - alternatively: platinum family or platinum metals - consist of six noble, precious metallic elements clustered together in the periodic table: iridium, osmium, palladium, platinum, rhodium, and ruthenium. All these metals have very useful catalytic properties and are widely used as catalysts in industry. In the last 3 decades, the automotive industry has emerged as the principal consumer of PGMs, although many other applications of these elements are still very important. To illustrate the very large interest in the

${ }^{a}$ Faculty of Chemistry, University of Warsaw, 1 Pasteur St., 02-093 Warsaw, Poland. E-mail:jkrajczewski@chem.uw.edu.pl; akudel@chem.uw.edu.pl

${ }^{b}$ Institute of Physical Chemistry Polish Academy of Sciences, 44/52 Kasprzaka Str., 01224 Warsaw, Poland

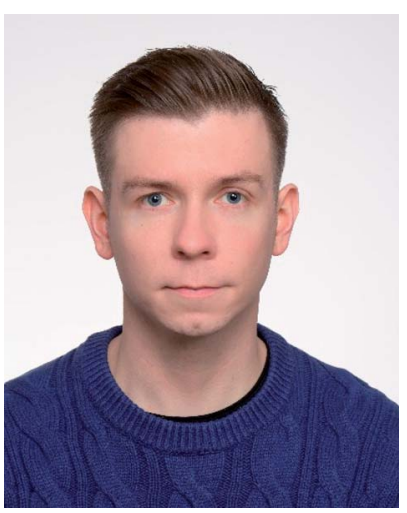

Jan Krajczewski is an associate professor in the Molecular Interactions and Spectroscopy group at the Faculty of Chemistry, University of Warsaw. His main research interest is the synthesis and characterization of metallic and plasmonic nanostructures and their application in optical spectroscopies. investigations of nanoparticles of PGMs we carried out a search in the Scopus database using the combination of the keyword "nanoparticle" and the keyword being the name of the metal (iridium, osmium, palladium, platinum, rhodium, and ruthenium). The number of articles found in the Scopus database that contain in the title or abstract these two keywords are as follows: for platinum nanoparticles $-18.2 \times 10^{3}$ articles, for palladium $-13.9 \times 10^{3}$, for ruthenium $-4.1 \times 10^{3}$, for rhodium $-2.4 \times 10^{3}$, for iridium $-1.3 \times 10^{3}$, and for osmium $-1.8 \times 10^{2}$ (results from January $1^{\text {st }} 2022$ ). The results of this search also show that nanoparticles of ruthenium, rhodium, iridium and osmium are investigated significantly less often than those formed from platinum and palladium.

In this review we describe the formation of unsupported and supported nanoparticles from less frequently used members of the platinum family (ruthenium, rhodium, osmium and

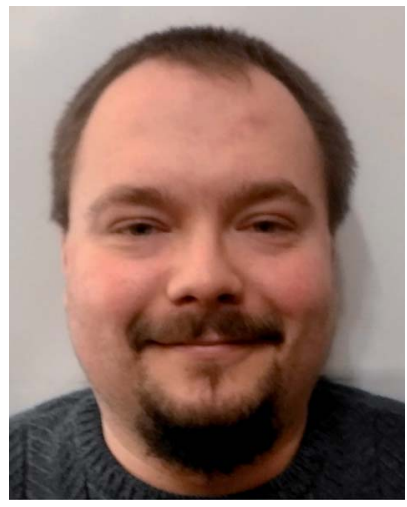

Robert Ambroziak is pursuing his PhD at the University of Warsaw, Poland. His main research interest is $S E R S$ and the synthesis of nanostructured semiconductor substrates coated with silver and gold nanomaterials. 
iridium). The example applications of such nanoparticles as catalysts have been also described - in order to maintain a close correlation between the parts devoted to the synthesis of nanoparticles and their catalytic applications, we describe mainly catalytic processes for which there is a clear dependence of the catalytic activity of the platinum-group nanoparticles on the method of their synthesis (changing mainly their size and shape).

Due to much larger number of publications devoted to $\mathrm{Pt}$ and Pd nanoparticles than devoted to nanoparticles of other PGMs, Pt and Pd nanoparticles will not be described in this review, because in the case of a review containing a description of all PGMs, the part devoted to the Pt and Pd nanoparticles would dominate the entire manuscript and to obtain the description of $\mathrm{Rh}, \mathrm{Ru}$, Ir and Os nanoparticles as detailed, as in this contribution, the whole review would to be very long. The less frequently used members of the platinum family have also, however, very interesting properties. For example, ruthenium is the most active catalyst of the Fischer-Tropsch synthesis, and rhodium is preferable to the other platinum metals in the reduction of nitrogen oxides to nitrogen. Because of very widespread use of rhodium in catalytic converters, the nowadays worldwide consumption of this metal is much greater than the nowadays consumption of ruthenium, iridium and osmium.

\section{Synthesis of unsupported ruthenium, rhodium, osmium and iridium nanoparticles}

\subsection{Ruthenium nanoparticles}

Ruthenium is a metal from the platinum family with the smallest atomic number. There is a possibility of formation of ruthenium nanoparticles having various shapes and sizes, however, as in a case of nanoparticles of other noble metals, in a majority of cases spherical or almost spherical ruthenium nanoparticles are formed. A commonly used method of formation of ruthenium nanoparticles is so-called polyol synthesis. In high temperatures, many polyols are able to reduce ions of noble metals to the metallic form. In polyol synthesis, a hot solution of a polyol solvent, like: ethylene glycol (EG), diethylene glycol (DEG), triethylene glycol (TrEG), or other

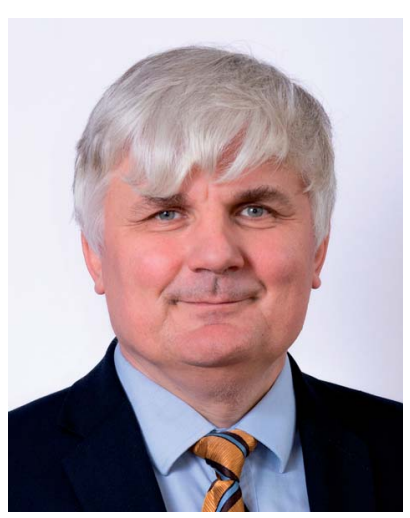

Andrzej Kudelski is a professor at the Faculty of Chemistry, the University of Warsaw, Poland. His area of expertise is nanotechnology and applications of surface-enhanced Raman scattering (SERS) especially in biochemical and medical analysis. polyethers (in general, polyethylene glycol - PEG) is used both as a solvent and a reducing agent. Addition of some compounds can significantly effects on stability, size, shape and outermost crystal facets of formed nanoparticles.

An interesting investigation of the formation of $\mathrm{Ru}$ nanoparticles in different polyols has been carried out by Yan and coworkers. ${ }^{1}$ Yan et al. heated to the boiling point solutions of $\mathrm{RuCl}_{3}$ and polyvinylpyrrolidone (PVP) in 3 various polyol solvents: EG, DEG and TrEG. Initially the color of all solutions was dark red and during heating changed to light yellow and then to dark brown. It suggests that the formation of $\mathrm{Ru}$ nanoparticles can be easily monitored by the UV-Vis spectrophotometry. Before heating, a polyol solution of $\mathrm{RuCl}_{3}$ and PVP exhibits absorption band at $347 \mathrm{~nm}$. During heating, the intensity of this absorption band decreases indicating reduction of $\mathrm{Ru}^{3+}$ ions. TEM analysis showed that the size of formed $\mathrm{Ru}$ nanoparticles decreases in the order EG > DEG > TrEG, it means, the size decreases when the temperature of the boiling point of the solvent increases (the boiling points of EG, DEG, and TrEG are: $197{ }^{\circ} \mathrm{C}, 244{ }^{\circ} \mathrm{C}$, and $285{ }^{\circ} \mathrm{C}$, respectively). This effect can be explained by the fact that when the temperature is lower, the reaction rate of the formation of the nucleation centers is lower, the number of the formed nucleation centers is smaller, and hence the formation of a smaller number of bigger nanoparticles is observed. However, not always such a simple correlation between the temperature, at which the reaction in a polyol solvent is carried out, and the size of the formed nanoparticles is observed. For example, the heating to the boiling point of the solution of ruthenium(III) acetylacetonate $\left(\mathrm{Ru}(\mathrm{acac})_{3}\right)$ and PVP in 1,4-butanediol (boiling point at $235^{\circ} \mathrm{C}$ ) leads to the formation of $\mathrm{Ru}$ nanoparticles with the diameter of $2.8 \mathrm{~nm}$, whereas when using EG (boiling point at $197^{\circ} \mathrm{C}$ ), the average diameter of the formed nanoparticles is $2.1 \mathrm{~nm} .^{2} \mathrm{UV}$-Vis measurements showed that the kinetic of the reduction of $\mathrm{Ru}(\mathrm{acac})_{3}$ in both solvents is similar, which suggests that these polyols have a similar efficiency in the reducing of $\mathrm{Ru}^{3+}$ ions.

The size of formed Ru nanoparticles also depends on the molar ratio of PVP and the ruthenium precursor - lowering this ratio leads to the formation of a larger ruthenium nanoparticles with a narrow size distribution, however, when the $\mathrm{PVP} / \mathrm{Ru}$ ratio is close to 1 or below, a precipitation of the formed Ru nanoparticles is often observed. Decreasing the amount of PVP in a solution allows for easier reduction of $\mathrm{Ru}^{3+}$ cations on the initially formed nucleation centers and hence the process of growth of nanoparticles occurs faster leading to formation of bigger nanoparticles (decreasing the time of the formation of nanoparticles also decreases the number of created nucleation centers).

Acetates are another stabilizers that can be used in an effective synthesis of ruthenium nanoparticles in a polyol environment. For example, Viau et al. formed ruthenium nanoparticles with very narrow particle diameter distribution by heating for 10 minutes of a polyol solution of $\mathrm{RuCl}_{3}$ and acetates. $^{3}$ The reaction temperature was set in a range between $140{ }^{\circ} \mathrm{C}$ and $180^{\circ} \mathrm{C}$. The size of formed nanoparticles depends on the reaction temperature and on the concentration of acetate ions. Generally, higher reaction temperature leads to formation 
of smaller nanoparticles. As for PVP, a high concentration of acetates reduces the growth rate of nanoparticles and thus extends the duration of the process of formation of nanoparticles, allowing for creation of more nucleation centers. For this reason, formation of a larger amount of smaller nanoparticles is observed.

Ruthenium in the bulk form has hexagonal close-packed (hcp) crystallographic structure, and such a structure have also typical Ru nanoparticles. In 2013 Kitagawa et al. reported that by changing the $\mathrm{Ru}$ precursor and the polyol solvent it is possible to produce using a simple polyol method $\mathrm{Ru}$ nanoparticles having either hcp or fcc (face-centered cubic) crystallographic structures. ${ }^{4}$ Kitagawa et al. found that heating the $\mathrm{Ru}(\mathrm{acac})_{3}$ solution in TrEG to $200{ }^{\circ} \mathrm{C}$ leads to formation of $\mathrm{Ru}$ nanoparticles having fcc crystallographic structure, while heating the solution of $\mathrm{RuCl}_{3}$ in $\mathrm{EG}$ leads to formation of $\mathrm{Ru}$ nanoparticles having hep crystallographic structure. ${ }^{4}$ Undoubtedly it is important result because $\mathrm{Ru}$ nanoparticles having different crystallographic structures exhibit significantly different catalytic activity. Example TEM images of fcc and hcp $\mathrm{Ru}$ nanoparticles and the corresponding XRD patterns are presented in Fig. 1. Alternative ways of formation of ruthenium nanostructures having the fcc crystallographic structure are significantly more complex, as, for example, the epitaxial growth of $\mathrm{Ru}$ shell on $\mathrm{Pd}-\mathrm{Cu}$ alloy nanoparticles. ${ }^{5}$ In such synthesis, $\mathrm{Pd}-\mathrm{Cu}$ nanoseeds were prepared by heating at $120{ }^{\circ} \mathrm{C}$ of the $\mathrm{Pd}(\mathrm{acac})_{2}$ and $\mathrm{CuCl}_{2}$ oleylamine ethanol solution with 1octadecylene as a reducing agent. Subsequently, $\mathrm{RuCl}_{3}$ was added and the temperature of the reaction mixture was increased to $200{ }^{\circ} \mathrm{C}$. TEM analysis revealed formation of the nanoparticles having homogeneous truncated octahedral shape and uniform size of $19.6 \pm 0.8 \mathrm{~nm}$. The epitaxial growth was initially induced by the galvanic replacement between the $\mathrm{Ru}$ precursor and $\mathrm{PdCu}_{3}$ seeds, during which the $\mathrm{Pd}-\mathrm{Cu}$ seeds gradually adopts a $\mathrm{Pd}-\mathrm{Cu} @ \mathrm{Ru}$ core-shell structure. Extending the heating time to 12 hours leads to formation of core-shell structures with the average core size of $14.9 \mathrm{~nm}$ and the shell thickness of $2.9 \mathrm{~nm}$. Similar method to grow fcc ruthenium, which is thermodynamically unfavorable in a bulk form, was proposed by Ye et al. ${ }^{6}$ In this case, epitaxial growth of the Ru layer was realized on palladium truncated nanooctahedrals and nanocubes prepared using a polyol method. Subsequently, to the above sols of the Pd nanoparticles, a proper amount of $\mathrm{RuCl}_{3}$ and PVP was added. Then, ascorbic acid as a reducing agent was added and the obtained solution was heated to $200{ }^{\circ} \mathrm{C}$ under magnetic stirring. In order to obtain ruthenium nanoframes instead of the core-shell structures, formed Pd@Ru nanoparticles were placed in aqua regia which led to the selective removing of the palladium cores. Fig. 2 a shows the general scheme of the formation of Ru nanoframes using this method. In a case of $\mathrm{Ru}$ nanostructures growth on Pd truncated octahedrals, detailed investigations proved that the formed $\mathrm{Ru}$ nanostructures actually exhibits fcc crystallographic structure and the dominant crystal facets are (100) at corners, (110) at edges and (111) at side faces, while, in a case of nanocubes, the dominant crystal facet is (100). ${ }^{6}$ Interestingly, Ru nanoparticles obtained in the same conditions but in an absence of Pd nanoseeds, have a shape of wavy nanowires and have a typical for ruthenium hcp crystallographic structure. ${ }^{6}$ TEM images of formed $\mathrm{Ru}$ nanoframes are presented on Fig. $2 \mathrm{~b}$ and $\mathrm{c}$.

Ruthenium nanoparticles have been also prepared in many other organic solvents. For example, Can and Metin prepared nearly monodisperse ruthenium nanoparticles by the reduction of $\mathrm{Ru}(\mathrm{acac})_{3}$ at $300{ }^{\circ} \mathrm{C}$ in a mixture of oleylamine and benzyl
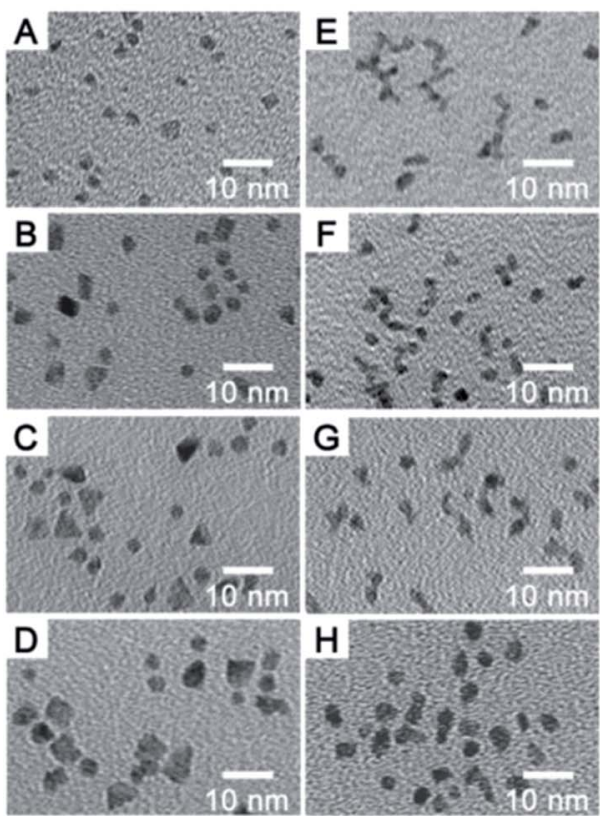

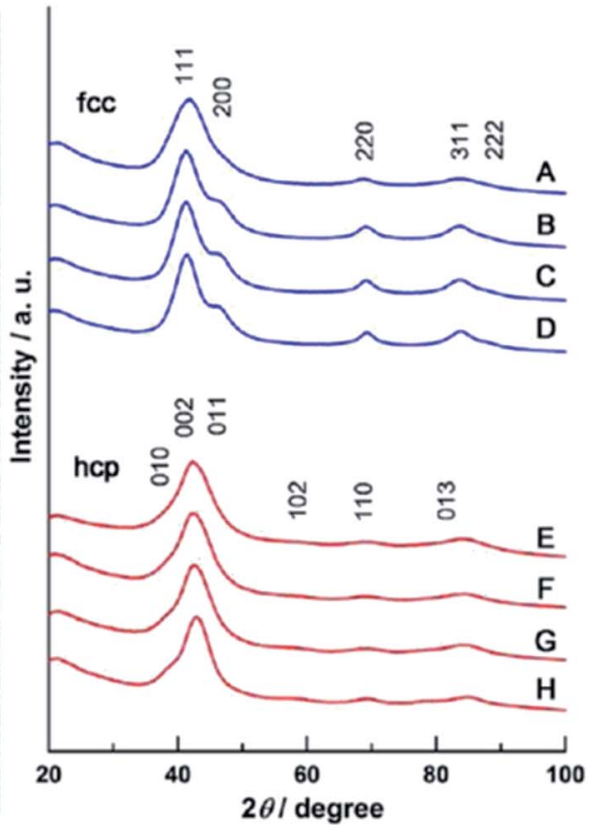

Fig. 1 (A-D) TEM images of various Ru nanoparticles having fcc structure. (E-H) TEM images of various Ru nanoparticles having hcp structure. Right panel shows corresponding XRD patterns. Reprinted with permission from ref. 4. Copyright 2013 the American Chemical Society. 

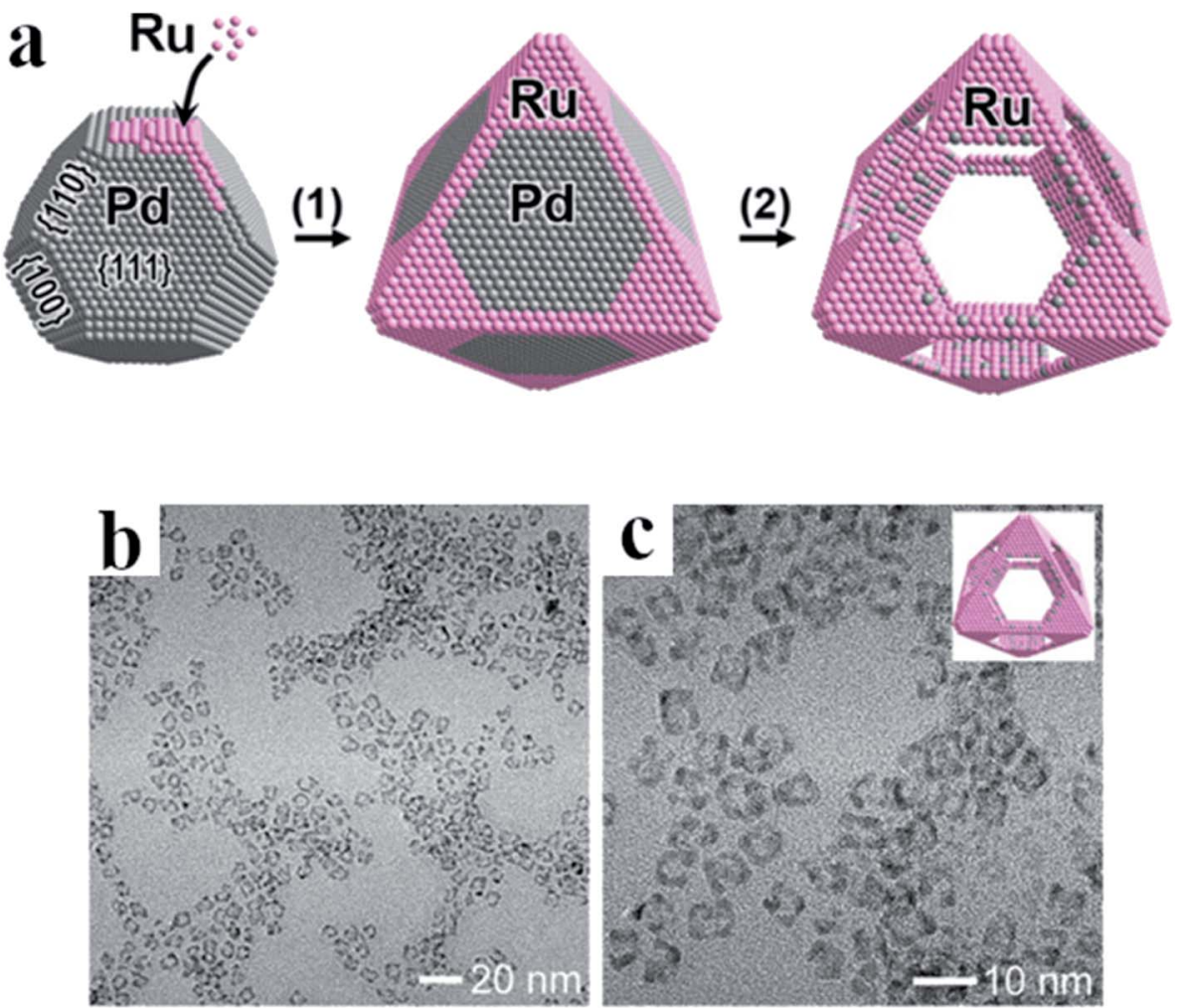

Fig. 2 (a) General scheme showing the formation of Ru nanoframes: (1) nucleation of Ru on tops and edges of Pd nanoparticles, (2) etching of the Pd core. (b) and (c) TEM images (with lower and higher magnification, respectively) of Ru nanoframes obtained after Pd etching. Reprinted with permission from ref. 6. Copyright 2016 the American Chemical Society.

ether. ${ }^{7}$ Oleylamine plays here a dual role as surfactant and a reducing agent, while benzyl ether is used as a solvent boiling at a high temperature. TEM analysis showed very narrow size distribution of formed nanoparticles with the average diameter of $2.5 \mathrm{~nm}$ and with $12 \%$ standard deviation. ${ }^{7}$ Another strategy for the preparation of $\mathrm{Ru}$ nanoparticles with the tunable sizes ranging from 2.6 to $51.5 \mathrm{~nm}$ has been developed by Zhao et al. ${ }^{8}$ In this method, $\mathrm{RuCl}_{3}$ is used as a ruthenium precursor, PVP as a stabilizing agent and propanol is both a reducing agent and a solvent. A lower reaction temperature results in a slower formation of nucleation centers and thus larger $\mathrm{Ru}$ nanoparticles are generated. For example, the average diameter of nanoparticles formed at $98{ }^{\circ} \mathrm{C}$ is estimated as $2.6 \pm 0.5 \mathrm{~nm}$, nanoparticles formed at $70{ }^{\circ} \mathrm{C}$ have the average diameter of 4.5 $\pm 0.9 \mathrm{~nm}$, whereas those formed at $30^{\circ} \mathrm{C}$ have the average diameter of $51.5 \pm 3.2 \mathrm{~nm}$. Additionally, sizes of formed $\mathrm{Ru}$ nanoparticles decreases when $\mathrm{pH}$ of the solution is increasing because increasing in $\mathrm{pH}$ leads to increasing in the reduction ability of propanol.

Ruthenium nanoparticles of regular spherical shape (in some cases also having sponge-like structure) with various size can be obtained by the decomposition of (1,5cyclooctadiene)(1,3,5-cyclooctatriene)ruthenium precursor under the $\mathrm{H}_{2}$ atmosphere (3 bar) in various alcohols or in an alcohol/THF mixture as a solvent. ${ }^{9}$ This reaction can be carried out without using further stabilizers and can be completed already after 45 minutes. The size of formed nanoparticles can be controlled in the range of $4-85 \mathrm{~nm}$ by the adjusting of the reaction temperature or by changing the composition of the solvent mixture. In line with previous reports, a higher reaction temperature leads to formation of smaller Ru nanoparticles.

$\mathrm{Ru}$ nanoparticles can be also formed at room temperature using a strong reducing agent. Such method of synthesis of Ru nanoparticles was realized, for example, by Abo-Hamed et al., who synthesized $1.2 \mathrm{~nm}$ ruthenium nanoparticles in an waterethanol solution using sodium borohydride as a reducing agent. ${ }^{10}$ Ruthenium nanoparticles have been also prepared at $21{ }^{\circ} \mathrm{C}$ by the sonochemical reduction of a ruthenium chloride solution using ultrasound frequencies in the range of 20-1056 $\mathrm{kHz}^{11}$ The proposed mechanism of this reaction is radical, sonolysis of water solution leads to formation of $\mathrm{H}^{*}$ and $\mathrm{OH}^{*}$ radicals which can reduce $\mathrm{Ru}^{3+}$ ions to the metallic form. The $\mathrm{Ru}$ nanoparticles produced by this ultrasound reduction have diameters between 10 and $20 \mathrm{~nm}$ as measured by the TEM imaging.

In many cases, using an organic solvent is undesirable due to various factors, like matrix effects or contamination of formed nanostructures by some organic compounds. Therefore, synthesis of metal nanoparticles in aqueous environment is often highly desirable and such methods of synthesis are continuously intensively developed. Ruthenium nanoparticles can be formed in aqueous solution, for example, by the reduction of $\mathrm{RuCl}_{3}$ by sodium borohydride. ${ }^{12}$ In the case of this synthesis, the $\mathrm{pH}$ of the reaction mixture should be lower than 
4.9 - higher $\mathrm{pH}$ (too large increase in $\mathrm{pH}$ can be generated, for example, by the addition of too large amount of sodium borohydride) induces precipitation of Ru nanoparticles. The formed nanoparticles have narrow size distribution and their average size is $1.8 \mathrm{~nm}^{12}$

\subsection{Rhodium nanoparticles}

In the platinum family, rhodium is the next element in terms of atomic number, after ruthenium. As in the case of ruthenium, also rhodium nanoparticles are often obtained by the polyol synthesis using $\mathrm{RhCl}_{3}$ as a source of $\mathrm{Rh}^{3+}$ ions, PVP as a stabilizing agent, and polyol (usually EG) as a solvent and a reducing agent. ${ }^{13}$ For example, Hoefelmeyer et al. formed small Rh nanocrystal seeds by the reduction of $\mathrm{RhCl}_{3}$ in EG in the presence of PVP and then, these seeds were further growth to form larger rhodium nanoparticles. ${ }^{13}$ It was found that the reaction temperature strongly effects on the process of growth of Rh nanoparticles. Growth of $\mathrm{Rh}$ nanocrystal seeds carried out at $190{ }^{\circ} \mathrm{C}$ leads to the formation of isotropic cubic nanoparticles with an average edge length of $12.7 \pm 1.5 \mathrm{~nm}$. Lowering the reaction temperature results in slightly different growth of $\mathrm{Rh}$ nanostructures, for example, at $140{ }^{\circ} \mathrm{C}$ Rh cubes with horns were formed, while at $90{ }^{\circ} \mathrm{C}$ multipods are synthetized. In temperatures lower than $90{ }^{\circ} \mathrm{C}$, growth of $\mathrm{Ru}$ seeds does not occur. High resolution TEM and XRD analysis showed that the formed $\mathrm{Rh}$ cubes and multipods are single nanocrystals. Rhodium multipods have a central region of $3 \mathrm{~nm}$ in diameter and two to seven arms with length from 3 to $9 \mathrm{~nm}$. It was found that also changing other (in addition to the reaction temperature) reaction parameters can strongly effect on the final geometry and size of produced nanoparticles. For example, Watson et al. synthetized monodisperse Rh planar tripods with the arm length of $8 \mathrm{~nm}$ and the width of $3.5 \mathrm{~nm}$ by heating at $140{ }^{\circ} \mathrm{C}$ of a solution of $\mathrm{RhCl}_{3}$ and PVP in EG (the process was carried out under a continuous nitrogen flow and the solution was stirred). ${ }^{14}$ Analogous planar tripod Rh structures were also obtained using $\mathrm{Na}_{3} \mathrm{RhCl}_{6}$ as a rhodium precursor. ${ }^{15,16}$ However, when trimethyl(tetradecyl)ammonium bromide (TTAB) is added to the $\mathrm{RhCl}_{3}$ and PVP solution in EG, heating of the obtained mixture leads to the formation of monodispersed Rh nanocubes. ${ }^{17}$ In a polyol synthesis one can also obtain starfish-like $\mathrm{Rh}$ nanocrystals with five wined arms. ${ }^{18}$ In the case of this synthesis, a solution of $\left[\left(\mathrm{CF}_{3} \mathrm{COO}\right)_{2} \mathrm{Rh}\right]_{2}$ and PVP in EG was heated to $180{ }^{\circ} \mathrm{C}$ for 6 hours. TEM analysis showed that the overall size of formed $\mathrm{Rh}$ nanoparticles was $30 \mathrm{~nm}$, arms were 4-10 $\mathrm{nm}$ in width and 6-12 $\mathrm{nm}$ in length. TEM analysis also showed that the arms grew from the corners of a five-fold twinned decahedral cores. ${ }^{18}$ In a similar manner, the Rh decahedrons can be formed with $80-90 \%$ efficiency. ${ }^{19}$ In this case, $\mathrm{Rh}(\mathrm{acac})_{3}$ and PVP solution in tetraethylene glycol was heated at $250{ }^{\circ} \mathrm{C}$ for 1 hour. The average size of formed Rh decahedrons was $15 \mathrm{~nm}$. Rhodium nanoparticles with the diameter in a range from 7 to $11 \mathrm{~nm}$ have been also formed at $220{ }^{\circ} \mathrm{C}$ in a solution of $\mathrm{Rh}(\mathrm{acac})_{3}$, sodium citrate and PVP in 1,4-butanediol. ${ }^{\mathbf{2 0}}$

In contrast to $\mathrm{Ru}$ nanoparticles, where hcp crystallographic structure is preferred (as for a bulk form), in a case of Rh nanoparticles the dominant crystallographic structure is thermodynamically stable for a bulk metal fcc structure. However, as in a case of ruthenium, it is possible to produce rhodium nanoparticles with different crystallographic structure than that of the bulk form. The first example of synthesis of Rh nanoparticles with the hcp crystallographic structure has been reported by Huang et al. in 2017. ${ }^{21}$ This group formed hep Rh nanoparticles from $\mathrm{Rh}(\mathrm{acac})_{3}$ precursor dissolved in oleylamine (the process was carried out at $220{ }^{\circ} \mathrm{C}$ )..$^{21}$

$\mathrm{Rh}$ nanoparticles have been also prepared in anhydrous ethanol and anhydrous methanol, for example, by placing a solution of $\mathrm{RhCl}_{3}$ in these solvents in a polyfluoroethylenelined stainless steel bomb and heating the sample at $175{ }^{\circ} \mathrm{C}-$ this process was carried out under high pressure auto-generated in such conditions. ${ }^{22}$ TEM analysis revealed that the size of formed Rh nanoparticles was in the range between 2 and $10 \mathrm{~nm}$. The another organic solvent used for the synthesis of $\mathrm{Rh}$ nanoparticles is dimethylformamide. For example, Behr et al. synthesized Rh nanoparticles showing narrow size distribution from 2.7 to $4.8 \mathrm{~nm}$ by the reduction at $80{ }^{\circ} \mathrm{C}$ of $\mathrm{Rh}(\mathrm{acac})(\mathrm{CO})_{2}$ dissolved in dimethylformamide by the hydrogen under the pressure of 10 bar. $^{23}$

Rhodium nanoparticles were also prepared in aqueous solution, for example, by the reduction of $\mathrm{RhCl}_{3}$ by sodium borohydride in a presence of PVP or $N$-alkyl- $N$-(2-hydroxyethyl) ammonium salts (with alkyl chain containing between 12 and 18 carbon atoms). ${ }^{24}$ This process, carried out at $20{ }^{\circ} \mathrm{C}$ under a nitrogen flow, is virtually instantaneous and induces very quick change of the color of the reaction mixture from intense red to black. The average diameter of formed $\mathrm{Ru}$ nanoparticles was $2.1 \mathrm{~nm} .{ }^{24} \mathrm{~A}$ similar method of the synthesis of Rh nanoparticles in an aqueous environment (reduction of $\mathrm{RhCl}_{3}$ by sodium borohydride in a presence of PVP) was carried out by Ewers and co-workers. ${ }^{25}$ TEM analysis of the Rh nanoparticles formed using PVP as a stabilizing agent, showed that the produced nanoparticles consist of two fractions: smaller nanoparticles with the average diameter of $2.6 \mathrm{~nm}$, and significantly larger nanoparticles with a diameter in a range between 12 and $70 \mathrm{~nm}$. It was also found that the molecular weight of PVP does not effect on the shape of formed nanoparticles, however, when PVP with a lower molecular mass is used, the average diameter of formed nanoparticles is smaller. Ewers and co-workers introduced to the reaction mixture also the second surfactant: sodium dodecyl sulfate. ${ }^{25}$ In this case, the formed Rh nanoparticles have the average diameter of $35 \pm 7 \mathrm{~nm}$ and their size distribution was significantly narrower.

Some groups synthesized Rh nanoparticles in a mixture of an organic solvent and water. For example, Harada et al. synthesized 2-3 nm rhodium nanoparticles stabilized by PVP in waterethanol mixture by the reduction of $\mathrm{Rh}^{3+}$ ions at hightemperature and high-pressure. ${ }^{26}$ Rhodium nanoparticles can be also obtained in a mixture of water and methanol at the atmospheric pressure. For example, Baeza et al. formed ruthenium nanoparticles mostly pseudo - spherical in shape and with narrow size distribution in a range from 1.9 to $4.9 \mathrm{~nm}$, by heating under reflux for $5 \mathrm{~h}$ at $90^{\circ} \mathrm{C}$ (or at $95^{\circ} \mathrm{C}$, when methanol 
concentration was lower) a mixture composed from: $\mathrm{RhCl}_{3}$, aqueous solution of $\mathrm{HCl}, \mathrm{PVP}$, and methanol. ${ }^{27}$

For some applications microporous or mesoporous metallic nanoparticles seems to be significantly better than the standard solid nanostructures. Mesoporous $\mathrm{Rh}$ nanoparticles have been synthetized by Jiang et al. by the reduction of $\mathrm{Na}_{3} \mathrm{RhCl}_{6}$ by ascorbic acid in a presence of polymeric micelle templates from poly(ethylene oxide)- $b$-poly(methyl methacrylate) ${ }^{28}$ The schematic mechanism of the formation of mesoporous Rh nanoparticles is presented in Fig. 3a, whereas TEM images of formed nanoparticles are presented in Fig. $3 \mathrm{~b}$ and $\mathrm{c}$. Used polymeric micelle network plays a role of a pore-directing agent and template that directs the formation of uniformly sized mesoporous Rh nanoparticles. High surface area of the formed mesoporous $\mathrm{Rh}$ nanoparticles was thermally stable up to $400{ }^{\circ} \mathrm{C} .^{28}$

Nanoparticles composed of two or more different metals are for some applications (for example catalytic ones) significantly better than those composed of only one element. One can find very large number of articles concerning synthesis of alloy or core-shell bimetallic nanostructures containing at least one metal from the platinum family. In some cases such nanoparticles are formed only from PGMs. Although, in these cases, nanoparticles are usually formed from alloys of platinum or palladium, there are also examples of synthesis of bimetallic nanoparticles composed only from less frequently used members of the platinum family (usually from alloys of: $\mathrm{Ru}-\mathrm{Rh}$, Ir-Rh, Ir-Ru and Os-Ru). For example, in 2015 Rakap described very simple synthesis of $3.4 \pm 2.0 \mathrm{~nm}$ alloy $\mathrm{Ru}-\mathrm{Rh}$ nanoparticles. ${ }^{29}$ The applied synthesis procedure involved: dissolution of $\mathrm{RhCl}_{3}, \mathrm{RuCl}_{3}$, and PVP in the absolute ethanol and longterm heating of the obtained solution.

\subsection{Iridium nanoparticles}

Iridium and osmium nanoparticles are synthesized not so often as $\mathrm{Rh}$ and $\mathrm{Ru}$ nanostructures. Nevertheless, many different approaches to synthetize the Ir and Os nanoparticles can be found in the literature.

Monodisperse and uniform iridium nanoparticles are often synthesized in an aqueous solution. For example, Cui et al. synthesized $3.5 \pm 0.5 \mathrm{~nm}$ Ir nanoparticles by the addition of aqueous solution of sodium borohydride to the aqueous solution containing $\mathrm{IrCl}_{3}$ and tannic acid. ${ }^{30}$ This reaction can be easily monitored by the UV-Vis spectrophotometry. Aqueous

\section{a}
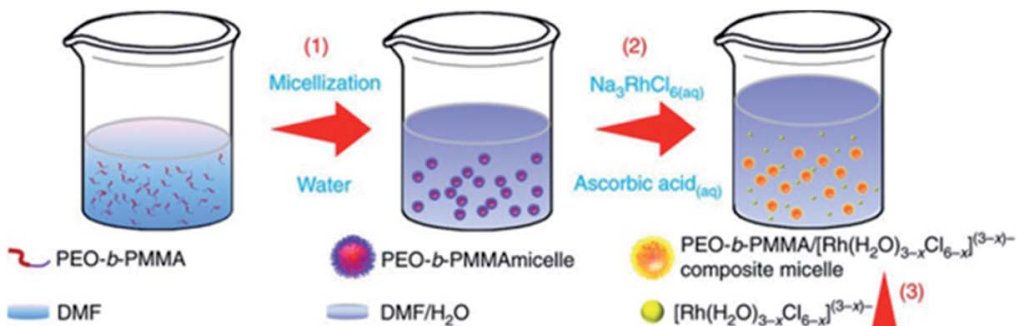

$\sim \mathrm{DMF}$

$=\mathrm{DMF} / \mathrm{H}_{2} \mathrm{O}$

composite micelle

(3)

$\left[\mathrm{Rh}\left(\mathrm{H}_{2} \mathrm{O}\right)_{3-x} \mathrm{Cl}_{6-x}\right]^{(3-x)-}{ }_{\text {Nucleation }}^{(3)}$

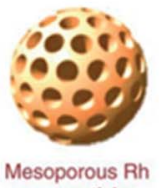

(5)
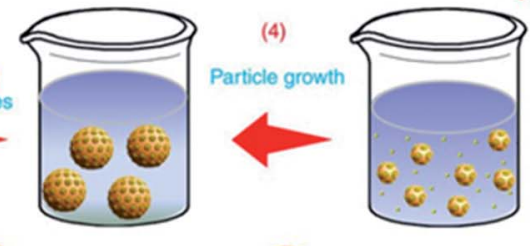

Mesostructured Rh

Mesostructured Rh (initial stage)
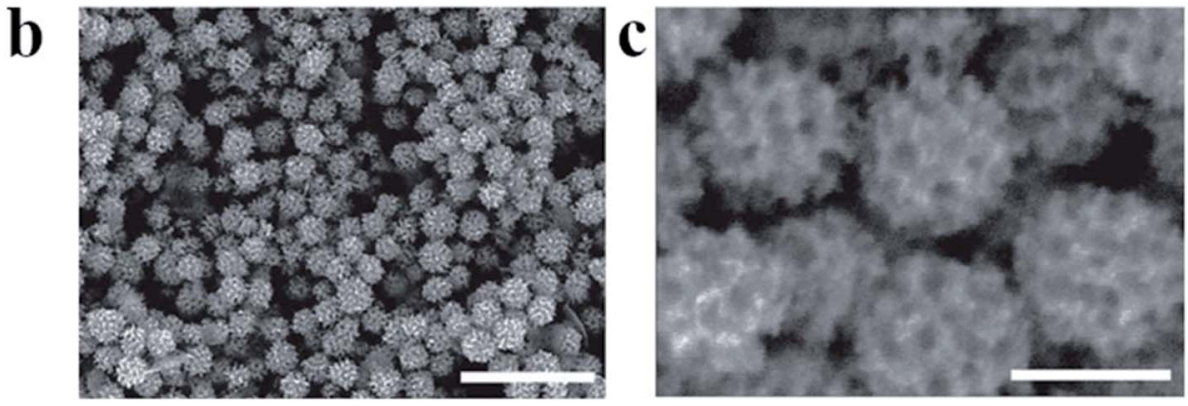

Fig. 3 (a) Illustration showing the mechanism of the formation of mesoporous Rh nanoparticles. Poly(ethylene oxide)- $b$-poly(methyl methacrylate) was used to form soft micelle templates, $\mathrm{Na}_{3} \mathrm{RhCl}_{6}$ was used as Rh precursor, and ascorbic acid as a reducing agent. The reaction was carried out in a mixture of dimethylformamide and water. (b) and (c) TEM images of Rh mesoporous nanoparticles with lower and higher magnification, respectively. Scale bare is $500 \mathrm{~nm}$ for image (b) and $100 \mathrm{~nm}$ for image (c). Reprinted from ref. 28. Creative Commons Attribution 4.0 International License. 
solution of $\mathrm{IrCl}_{3}$ is yellow and in the UV-Vis absorption spectrum of this solution one can observe two bands at 421 and $486 \mathrm{~nm}$. The color of the sol of Ir nanoparticles is dark brown. Cui et al. developed another method of synthesis of iridium nanoparticles in an aqueous solution. ${ }^{31}$ In this case, iridium chloride, trisodium citrate and $\mathrm{NaOH}$ was dissolved in water and heated to boiling under reflux. During this heating the solution changes color from green to faint blue and then to faint yellow. After 20 minutes sodium borohydride was added, heater was switched off, and the solution was gradually cooled down to a room temperature. The final solution was yellow brown. The average diameter of formed Ir nanoparticles estimated from the TEM analysis is $2.5 \pm 0.5 \mathrm{~nm} .^{31}$

As nanoparticles of all PGMs, iridium nanoparticles can be synthesized in organic solvents. For example, refluxing for 6 hours of the ethanolic solution of $\mathrm{IrCl}_{3}$ and PVP leads to the formation of pale yellow solution containing approximately spherical nanoparticles with an average size of about $1.5 \mathrm{~nm} .^{32}$

An interesting method of the synthesis of iridium nanoparticles is a photochemical synthesis developed by Kundu and Liang. ${ }^{33}$ This group irradiated for 4 hours using UV radiation of an aqueous solution containing: $\mathrm{IrCl}_{3}, \mathrm{NaOH}$, hexadecyltrimethylammonium bromide (CTAB) and 2,7-dihydroxynapthalene (2,7-DHN). Illumination with UV radiation excites the photosensitizer molecules (2,7-DHN) what leads to the formation of radicals, that are able to reduce $\operatorname{Ir}^{3+}$ ions into the metallic form. The shape of formed nanoparticles depends on the concentration ratio between $\mathrm{CTAB}$ and $\mathrm{IrCl}_{3}$. It was observed that at lower CTAB concentrations, mostly approximately spherical nanoparticles were formed, while in a case of higher concentrations, nanoparticles with anisotropic shapes were formed. This is caused by the adsorption of CTAB molecules on the surface of nanoparticles which leads to the reduction of the growth rate of different crystal plates. ${ }^{33}$

Cubic iridium nanoparticles without any surfactants on the surface can be synthesized at room temperature by the galvanic replacement reaction. ${ }^{34}$ For this purpose, a drop of an aqueous solution containing a proper amount of $\mathrm{IrCl}_{3}$ and $\mathrm{CuCl}_{2}$ has been injected on a $\mathrm{Cu}$ foil. The size of the formed Ir nanocubes varies from 120 to $200 \mathrm{~nm}$ with the average edge length of $158 \mathrm{~nm}^{34}$

Nanoparticles with well-defined iridium crystal facets can be obtained, for example, by the deposition of iridium layer on some regular palladium nanoparticles. ${ }^{35}$ Using cubic and octahedral Pd nanoparticles encased by $\{100\}$ and $\{111\}$ facets, respectively, as the seeds, it is possible to generate Pd@Ir cubic and octahedral nanoparticles with $\operatorname{Ir}\{100\}$ and $\operatorname{Ir}\{111\}$ facets. Cuboidal or octahedral palladium nanoparticles were prepared by the standard polyol synthesizes. For deposition of the iridium layer, EG solution containing PVP and ascorbic acid was heated at $100{ }^{\circ} \mathrm{C}$ for $1 \mathrm{~h}$. Subsequently, a proper amount of palladium nanoparticles was added and the temperature was increased to the boiling point of EG. Immediately after the temperature of the boiling point of EG had been reached, a proper amount of $\mathrm{Na}_{3} \mathrm{IrCl}_{6}$ was introduced to the reaction mixture. TEM analysis showed that the formed Pd@Ir nanocubes had the average edge length of $7.5 \mathrm{~nm}$, which is $1.5 \mathrm{~nm}$ greater than that of the initial Pd nanocubes. Therefore, the thickness of the deposited iridium layer was estimated on $0.75 \mathrm{~nm}$. Crystallographic studies proved that the Ir surfaces formed on Pd@Ir nanocubes has $\{100\}$ orientation, while in a case of octahedral Pd@Ir nanoparticles the dominant facet is $\{111\} .{ }^{35}$

\subsection{Osmium nanoparticles}

Osmium nanoparticles are often synthesized in aqueous solutions. For example, Chakrapani and Sampath prepared osmium nanostructures by the reduction of an aqueous solution of $\mathrm{OsCl}_{3}$ by ascorbic acid. ${ }^{36}$ This reaction was carried out for 90 minutes at $95{ }^{\circ} \mathrm{C}$. SEM analysis showed that the synthetized nanomaterial contains nanochains formed by the connected together practically spherical 1-1.5 nm Os nanoparticles. The sol of such Os nanochains is violet (with the extinction band at $540 \mathrm{~nm}$ ), and the formed nanostructures has plasmonic properties and can be used for surface-enhanced Raman scattering (SERS) measurements. Another method of synthesis of Os nanoparticles in an aqueous medium was developed by Ede et al. ${ }^{37}$ In this case, the formation of osmium nanoparticles was realized at room temperature by the reduction of $\mathrm{OsO}_{4}$ by 2,7DHN in a presence of CTAB. This process takes place only after alkalization of the reaction mixture (realized by the addition of $\mathrm{NaOH}$ : the pale violet solution of $\mathrm{OsO}_{4}$ and 2,7-DHN becomes dark after addition of $\mathrm{NaOH}$ ). Ede et al. assume that the formation of Os nanoparticles occurs in a several steps. At first, after alkalization of the reaction mixture, the perosmate anions $\left(\left[\mathrm{OsO}_{4}(\mathrm{OH})_{2}\right]^{2-}\right)$ are formed. Such anions can be easily reduced in an alkaline solution to osmate anion $\left(\left[\mathrm{OsO}_{2}(\mathrm{OH})_{4}\right]^{4-}\right)$. Finally, osmate anions are reduced by 2,7-DHN and osmium nanoparticles are generated. The degree of the agglomeration of formed Os nanoparticles depends on the concentration of CTAB in a solution. As in the case of osmium nanoparticles formed by the reduction with ascorbic acid, ${ }^{36}$ the osmium generated by the reduction with 2,7-DHN can be also used as an effective substrate in SERS measurements. ${ }^{37}$

Although osmium in a bulk state adopts only hcp crystallographic structure, Wakisaka et al. showed that osmium nanoparticles with fcc crystallographic structure can be synthesized from osmium acetate in EG at $200{ }^{\circ} \mathrm{C} .{ }^{38}$ This reduction was realized in a presence of PVP and the average size of formed Os nanoparticles was estimated as $1.2 \pm 0.2 \mathrm{~nm} .^{38}$

\subsection{Key parameters influencing the size, shape and structure of nanoparticles}

To summarize the part of this article concerning synthesis of unsupported $\mathrm{Ru}, \mathrm{Rh}$, Ir and Os nanoparticles, the collected experimental details of some selected synthesis of such nanostructures are presented in Table 1 . The presented data illustrates how the change of the experimental conditions influences on the shape, size and the crystallographic structure of the formed nanostructures (see Table 1). Moreover, below we briefly summarize how the change of the stabilizing agent, metal precursor, solvent and the reaction temperate influence on the size, shape and the structure of the formed nanostructures.

2.5.1. Stabilizing agent. The type of a stabilizing agent usually plays a key role in the synthesis of metallic 
Table 1 The experimental details of the synthesis of various $\mathrm{Ru}, \mathrm{Rh}, \mathrm{Ir}$ and Os nanoparticles. Presented data illustrates how the change of the experimental conditions influences on the shape, size and the crystallographic structure of the formed nanoparticles

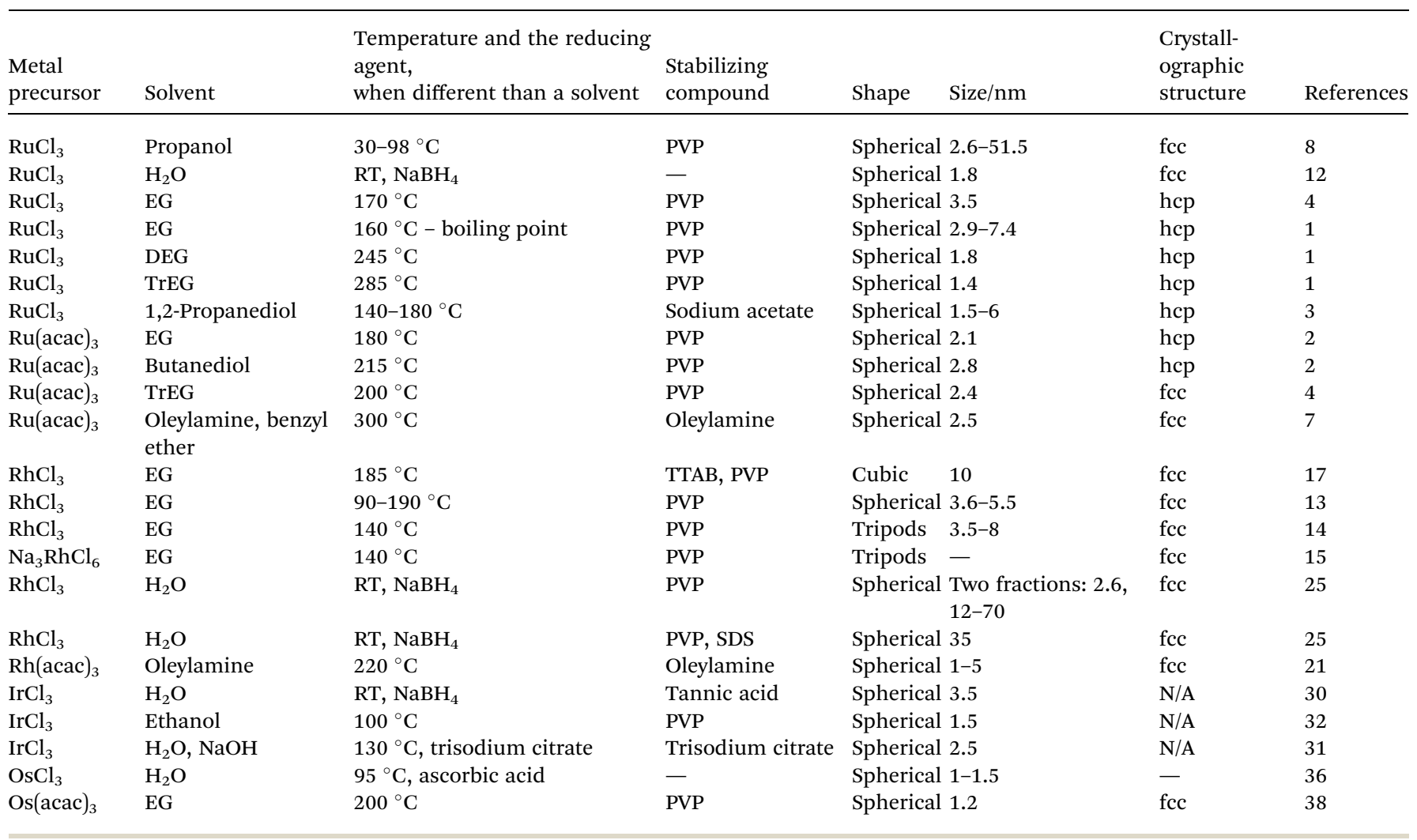

nanoparticles. Generally, when the interactions between the surface of the nanoparticles and the molecules of the stabilizing agent are stronger, the formed nanoparticles are smaller. ${ }^{39} \mathrm{It}$ can be well illustrated in a polyol synthesis, when the polarity of used polymeric stabilizing agent increases in an order: PVP $<$ PVA $<$ PEG (where PVA is polyvinyl acetate), the strength of the adsorption of the more polar stabilizing agents on the surface of the metallic nanoparticles increases, and hence, the formed metallic nanoparticles are smaller. ${ }^{39}$

The other important factor influencing the synthesis of metallic nanoparticles is concentration of a stabilizing agent. Generally, increasing the concentration of a stabilizing agent leads to formation of smaller nanoparticles. This is caused by the fact that the formed metallic seeds are directly surrounded by a larger number of molecules of a stabilizing agent. In a case of using polymeric macromolecules as stabilizing agents, the length of the polymeric chain is also an important factor effecting on the size of formed nanoparticles. Additionally, the increasing concentration of a stabilizing agent often leads to an increase in the solution viscosity. The increased viscosity makes diffusion more difficult and hence limits the growth of nanoparticles ${ }^{40}$ However, in many cases, it is a very small effect and therefore is often not considered. ${ }^{41}$

In a case of using polymeric macromolecules as stabilizing agents, the change of the molecular weight of the polymeric molecules usually also significantly influences on the stability of formed nanoparticles-nanoparticles stabilized by a polymeric stabilizing agent with a longer polymeric chain are usually more stable (longer polymeric molecules better keep metallic nanoparticles away from each other). ${ }^{42}$

2.5.2. Temperature. Typical synthesis of metallic nanoparticles can be divided into two subsequent processes: nucleation and growth. The kinetic of the nucleation process can be described by the $k_{1}$ constant rate, and the growth process can be described by the $k_{2}$ constant rate. Both constant rates are increasing with increasing temperature. However, it was found that the $k_{1}$ constant rate grows sharply in high temperatures, while the $k_{2}$ constant rate increases almost linearly with the reaction temperature. The influence of $k_{1}$ on the size of formed nanoparticles is indirect $\left(k_{1}\right.$ directly influences only the amount of formed nanoparticles) - the available metal precursor is consumed for formation of a different number of nanoparticles. As a result, it could be concluded that a decrease of the size of formed nanoparticles at higher temperatures is a result of sharply increased $k_{1}$ instead of the decreases of $k_{2} \cdot{ }^{43}$ It means that temperature plays a key role in practically all types of synthesis of metallic nanoparticles.

Another important parameter is a heating rate. Successive decreasing of the heating rate leads to formation of larger nanoparticles with a broader size distribution. ${ }^{44}$ This can be connected with a less defined nucleation threshold. As a result, more nuclei can be formed during a longer time, what leads to a broader size distribution. 
2.5.3. Type of metal precursor. Generally, simple metal's salts as chlorides, nitrates, sulfates, acetates or acetylacetonates are used as metal precursors in the synthesis of PGMs nanoparticles. The usefulness of a given compound mainly depends on two factors: its solubility (a sufficient solubility is needed to obtain an expected amount of the metal precursor in the reaction mixture) and the stability of metal complexes formed in the reaction solution. More stable complexes dissociate slower, what leads to an decrease of the reaction rate.

The rate of the addition of a metal precursor also effects on the final size of formed nanoparticles. The slower addition rate results in larger nanoparticles with a broader distribution of sizes. The slower addition rate induces a longer period of nucleation: immediately after injection a few nuclei are formed, while the precursor is continuously injected into the reaction mixture. Some of this precursor is converted into new nuclei and some is used for growing of pre-existed nuclei. Finally, the polydisperse particles with a large size are formed. ${ }^{45}$

2.5.4. Type of solvent and reducing agent. PGMs nanoparticles can be synthesized in many various solvents, therefore, it is impossible to form a simple general rule how the solvent used influences on the shape, size and the structure of formed nanoparticles. However, some rules when a given group of solvents is used can be noticed. For example, in many polyol methods, where the reduction of a metal precursor occurs in the boiling point of the solvent, the size of formed nanoparticles decreases when the temperature of the boiling point of the solvent increases. For example, in a case of Ru nanoparticles formed in EG, DEG and TrEG (the boiling points of EG, DEG, and TrEG are: $197{ }^{\circ} \mathrm{C}, 244^{\circ} \mathrm{C}$, and $285^{\circ} \mathrm{C}$, respectively) the smallest nanoparticles are formed in TrEG, while the biggest in EG. ${ }^{1}$ Here, the type of the solvent plays the same role as the temperature. When the temperature is lower, the rate of the seed formation is slower, and hence the number of the formed nucleation centers is smaller, and, as a result, the formation of a smaller number of bigger nanoparticles is observed. The same trend was also observed for other organic solvent like oleylamine, octadecylamine and benzyl ether. ${ }^{7,8}$

When solvent plays also a role of a reducing agent, not only its boiling temperature but also its reducing potential is very important - reducing potential determines the kinetics of the reduction reaction that influences sizes and shapes of formed nanoparticles. For example, Kaneko et al. analyzed the reducing potential of various diols and showed that their reducing potential strongly depends on the number of carbon atoms between the $-\mathrm{OH}$ groups: the smaller distance between the hydroxyl groups results in higher reducing ability. ${ }^{46}$ The reactivity of polyols with different positions of the hydroxyl groups are almost similar as far as the number of carbon atoms between them is the same.

In a case of synthesis in aqueous solutions, application of a stronger reducing reagent produces smaller metallic nanoparticles with narrower size distribution. ${ }^{47}$ This effect can be explained by faster nucleation process when a stronger reducing agent is used.

\section{Synthesis of ruthenium, rhodium, osmium and iridium nanoparticles attached to various supports}

Nanoparticles of PGMs are often synthesized in a presence of another material. Such approach often leads to the formation of PGMs nanoparticles strongly attached to various supports. Attachment of nanoparticles of PGMs to the support can be also realized after their formation.

There are many various reasons why nanoparticles of PGMs are attached to another materials. In many cases, the main reason of such attachment is modification of the electronic structure of the PGM nanoparticles, and hence, modification of some of their chemical (mainly catalytic) properties, induced by the PGM nanoparticles - support interactions. A significant modification of the catalytic properties of PGM nanoparticles is observed, for example, after their attachment to $\mathrm{TiO}_{2}$. The other very important reason of deposition of PGM nanoparticles on another materials is to facilitate their practical use, for example, as catalysts. When used as a heterogeneous catalyst, very expensive PGMs nanoparticles attached to some supports can be much easier and more efficiently removed from the reaction mixture after the completion of the reaction than the non-attached nanoparticles. For example, using a magnetic field easy manipulation of the PGM nanoparticles can be achieved when they are attached to a magnetic substrate. Below some examples of the synthesis of ruthenium, rhodium, osmium and iridium nanoparticles deposited on various supports are presented.

\subsection{Supported ruthenium nanoparticles}

Ruthenium nanoparticles can be deposited on various materials, for example, on graphene. To synthesize such a composite, Du et al. carried out co-reduction of $\mathrm{RuCl}_{3}$ and graphite oxide in EG using ascorbic acid as a reducing agent. ${ }^{47}$ Briefly, a solution of mentioned above compounds in EG was introduced to a stained steel autoclave and heated at $180^{\circ} \mathrm{C}$ for 5 hours. ${ }^{47}$ TEM analysis of the material obtained after this process revealed that the $\mathrm{Ru}$ nanoparticles with the average diameter of $1.9 \mathrm{~nm}$ were well dispersed on the graphene surface. Fig. 4 presents TEM images of the obtained Ru nanoparticles attached to the surface of graphene. Ruthenium nanoparticles are also sometimes formed on magnetic substrates like magnetic silica-functionalized nanospheres or microspheres. To obtain such a material, Baig and Varma at first synthesized $\mathrm{Fe}_{3} \mathrm{O}_{4}$ magnetic nanoparticles functionalized by tetraethyl orthosilica, then added to this sol under stirring $\mathrm{RuCl}_{3}$, and after that increased $\mathrm{pH}$ to $10 \mathrm{using}$ ammonia hydroxide and continued stirring for another 24 hours. ${ }^{48}$ TEM analysis confirmed formation of $\mathrm{Fe}_{3} \mathrm{O}_{4} @ \mathrm{SiO}_{2} \mathrm{Ru}$ nanoparticles with a spherical morphology and a size in the range of 15$30 \mathrm{~nm}$.

It is also possible to attach already formed nanoparticles to the surface of the support material. For example, ruthenium nanoparticles can be prepared using previously described polyol method (heating a solution of $\mathrm{RuCl}_{3}$ in 1,2-propanediol at 


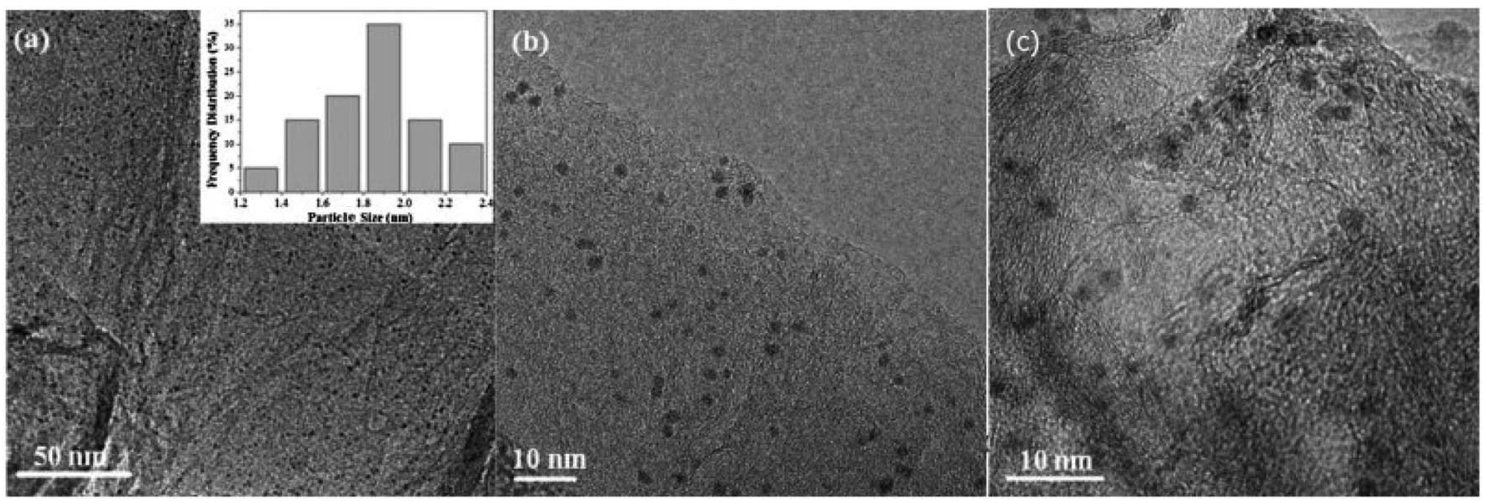

Fig. 4 TEM images of the Ru nanoparticles deposited on the surface of graphene: ( $a$ and b) before application as a catalyst and (c) after five cycles of the application of this material as a catalyst for the ammonia borane decomposition. Reprinted with permission from ref. 47 . Copyright 2015 the Elsevier.

$\left.150{ }^{\circ} \mathrm{C}\right)^{49}$ and then formed nanoparticles can be successfully immobilized on hydroxyapatite by heating a solution containing hydroxyapatite and $\mathrm{Ru}$ nanoparticles at $110{ }^{\circ} \mathrm{C}$.

As examples of other interesting materials, on which ruthenium nanoparticles have been deposited, one can mention: carbon nanotubes, ${ }^{\mathbf{5 0 , 5 1}}$ nitrogen-doped carbon nanofibers, ${ }^{52}$ or $\gamma-\mathrm{Al}_{2} \mathrm{O}_{3} \cdot{ }^{4}$

\subsection{Supported rhodium nanoparticles}

Rhodium nanoparticles are often deposited on various carbon materials, and in such cases $\mathrm{RhCl}_{3}$ is usually used as a rhodium precursor. For example, Pan and Wai deposited Rh nanoparticles with an average diameter of $2.5 \pm 0.7 \mathrm{~nm}$ on surfaces of carboxylate-functionalized multi-walled carbon nanotubes (MWCNTs) by a sonochemical reduction in an ethanol solution of $\mathrm{RhCl}_{3}, \mathrm{MWCNTs}$ and borane morpholine complex used as a reducing agent. ${ }^{53}$ It was found that when this synthesis is carried out without using of ultrasounds, formed $\mathrm{Rh}$ particles become very large and clumped. ${ }^{53}$ Reduction of $\mathrm{RhCl}_{3}$ by sodium borohydride in a presence of sodium citrate and carbon black allows to deposit Rh nanoparticles also on such carbon material. ${ }^{54}$ This reaction was carried out in an aqueous solution and leads to the formation of Rh nanoparticles with an average size of $4.1 \mathrm{~nm}$ and narrow size distribution well dispersed on the carbon surface. When reduction of $\mathrm{RhCl}_{3}$ is carried out without addition of sodium citrate, significantly bigger Rh nanoparticles were formed with the average size of $8.2 \mathrm{~nm}$ and with a broad size distribution from 3 to $16 \mathrm{~nm}$. Rhodium nanoparticles with the average size of $5.7 \pm 1.5 \mathrm{~nm}$ have been also deposited on reduced graphene oxide by the reduction at elevated temperature of $\mathrm{RhCl}_{3}$ by $\mathrm{H}_{2}$ in a presence of this carbon material. ${ }^{55}$ In some cases also other than $\mathrm{RhCl}_{3}$ rhodium compounds are used as rhodium precursors during deposition of $\mathrm{Rh}$ nanoparticles on carbon materials. For example, rhodium nanoparticles have been deposited on carbon nanofibers by the thermal decomposition of $\mathrm{Rh}_{4}(\mathrm{CO})_{12}$ in boiling toluene in a presence of carbon nanofibers. ${ }^{56}$
Rh nanoparticles are often deposited on various metal oxides like silica, alumina, titania, zirconia, hafnia or ceria. ${ }^{57}$ For example, to deposit rhodium nanoparticles on ceria, Akbayrak et al. mixed a proper amount of ceria with an aqueous solution of $\mathrm{RhCl}_{3}$. Subsequently, to the above mixture, aqueous solution of sodium borohydride was added dropwise. After 30 minutes of stirring, formed $\mathrm{Rh} / \mathrm{CeO}_{2}$ was isolated by centrifugation. TEM analysis showed that the average diameter of formed $\mathrm{Ru}$ nanoparticles was $3.2 \pm 0.8 \mathrm{~nm} .^{.7}$

A very important parameter in a case of nanocatalysts is catalyst recovery. Catalyst recovery allows for isolation of nanocatalyst from a reaction solution, purification and application of nanocatalyst for the next reaction cycle. One of the options of separation of nanostructures is centrifugation. However, in a case of small nanoparticles centrifugation can take a long time or even can be impossible. Therefore, one of a promising alternative is formation of conjugates of metallic nanoparticles of a catalyst and a magnetic matrix. An example of such a catalyst are rhodium nanoparticles on magnetic silicacoated $\mathrm{Fe}_{3} \mathrm{O}_{4}$ nanoparticles synthesized by Jacinto et al. ${ }^{58}$ In this case, $\mathrm{RhCl}_{3}$ was added to a solution of amino functionalized silica coated magnetic nanoparticles and injected for reduction at $75{ }^{\circ} \mathrm{C}$ in $\mathrm{H}_{2}$ at 6 bar. TEM analysis showed that the formed catalyst is composed of silica spheres that contains magnetic cores and $\mathrm{Rh}$ nanoparticles of about 3-5 $\mathrm{nm}$ decorating the silica shell.

\subsection{Supported iridium nanoparticles}

Iridium nanoparticles have been also deposited on many different materials, for example, on carbon nanotubes. ${ }^{59}$ To form such a composite, a solution of (acetylacetonato)(1,5cyclooctadiene)iridium(I) and carbon nanotubes in dichloromethane was placed in a stainless steel autoclave. Then, the introduced mixture was stirred and the solvent was slowly evaporated. Subsequently, autoclave was filled with hydrogen at 150 bar and was kept in these conditions for $12.5 \mathrm{~h}$, which led to the formation of Ir nanoparticles. It was found that the reaction temperature effects on the size and catalytic activity of formed Ir 
nanoparticles. At low temperature nucleation is slow and the nucleation occurs only after collision with an already existing nucleation seed, what leads to formation of large microparticles or microfilms, which are catalytically less active than the smaller nanoobjects. At higher temperature nucleation is significantly faster and hence formation of smaller nanoparticles with higher catalytic activity is observed. Du et al. proposed a slightly different method of deposition of Ir nanoparticles on carbon nanotubes: mixing carbon nanotubes with an aqueous solution of $\mathrm{H}_{2} \mathrm{IrCl}_{6}$, evaporation of water at $100{ }^{\circ} \mathrm{C}$, and then the final reduction of $\mathrm{H}_{2} \mathrm{IrCl}_{6}$ at $300{ }^{\circ} \mathrm{C}$ in $\mathrm{H}_{2} / \mathrm{Ar}$ atmosphere. ${ }^{60}$ The average size of formed Ir nanoparticles was about $1.9 \mathrm{~nm}$.

Another carbon material which had been applied as a support for Ir nanoparticles is graphene. Wu et al. formed Ir nanoparticles supported on graphene by the following three steps process: (1) sonication of a graphene oxide functionalized with dopamine (graphene oxide was synthesized by the Hummers' method) and $\mathrm{IrCl}_{3}$, (2) product collection by the centrifugation and (3) heating of the obtained mixture under $\mathrm{Ar}$ atmosphere to $750{ }^{\circ} \mathrm{C}$ and keeping the sample in this temperature for $3 \mathrm{~h}^{61}$ TEM measurements showed that the size of formed Ir nanoparticles was 2-3 nm. Similar approach for formation of Ir nanoparticles on graphene (however with using $\operatorname{Ir}(\text { acac })_{3}$, as a iridium precursor) has been applied by Cunci et $a{ }^{62}$ This group also found that the final size of Ir nanoparticles formed in such synthesis depends on the gas, in which the heating was realized. Samples heated in air exhibit a wide size dispersion of formed Ir nanoparticles in a range of 2$30 \mathrm{~nm}$, while heating in $\mathrm{N}_{2}$ atmosphere leads to the formation of small (1-4 nm) Ir nanoparticles.

Iridium nanoparticles have been also supported on nitrogenfunctionalized carbon (NC) matrix..$^{63,64}$ For this purpose, NC powder, ascorbic acid and hexachloroiridium acid was dispersed in EG. Obtained reaction mixture was transferred into a teflon-lined stainless steel autoclave and heat treated at $180^{\circ} \mathrm{C}$ for $5 \mathrm{~h}$. TEM analysis of the obtained product showed that the formed spherical Ir nanoparticles with a diameter of $1.4 \mathrm{~nm}$ are homogeneously dispersed on NC matrix without any significant signs of aggregation. ${ }^{64}$

In many cases iridium nanoparticles has been deposited on various oxides supports. For example, Fan et al. synthetized iridium nanoparticles supported on hydrous zirconia. ${ }^{65}$ At first, a solution containing: $\mathrm{NH}_{3}, \mathrm{ZrOCl}_{2}$ and $\mathrm{H}_{2} \mathrm{IrCl}_{6}$ has been aged for $12 \mathrm{~h}$ at $50{ }^{\circ} \mathrm{C}$, then the obtained product was filtered and washed with distilled water until no chlorine was found in an elution, and subsequently the obtained sample was reduced for $2 \mathrm{~h}$ by a pure hydrogen at the pressure of 40 bar and the temperature of $180^{\circ} \mathrm{C}$. TEM analysis showed formation of 2.5$5.0 \mathrm{~nm}$ Ir nanoparticles uniformly distributed over the substrate. Another oxide substrate, on which Ir nanoparticles has been deposited, were $\mathrm{MoO}_{3}$ nanorods. ${ }^{66}$ The $\mathrm{MoO}_{3}$ nanorods were obtained by the calcination of a $\mathrm{Mo}_{3} \mathrm{O}_{10}\left(\mathrm{C}_{6} \mathrm{H}_{8} \mathrm{~N}\right)_{2^{-}}$ $\cdot 2 \mathrm{H}_{2} \mathrm{O}$ precursor at $400{ }^{\circ} \mathrm{C}$ for $2 \mathrm{~h}$ under air flow. Then, the obtained $\mathrm{MoO}_{3}$ support was impregnated by an aqueous solution of $\mathrm{H}_{2} \mathrm{IrCl}_{6}$. After drying, the sample was reduced at $300{ }^{\circ} \mathrm{C}$ for $2 \mathrm{~h}$ using a stream of $5 \mathrm{vol} \% \mathrm{H}_{2} / \mathrm{Ar}$. TEM analysis showed that the formed Ir nanoparticles have a diameter of $2.5 \pm$ $0.1 \mathrm{~nm}$. $\mathrm{A} \mathrm{TiO}_{2}$ nanopowder has been also used as a support for Ir nanoparticles. In this case, a $\mathrm{TiO}_{2}$ nanopowder was mixed with an aqueous solution of $\mathrm{IrCl}_{4}$ hydrate and urea, the obtained suspension was heated to $80{ }^{\circ} \mathrm{C}$ and stirred at this temperature for 16 hours, then, the product was filtered, dried under vacuum and calcined at $400{ }^{\circ} \mathrm{C}$ for $2 \mathrm{~h}^{67}$ The average size of Ir nanoparticles formed on the surface of $\mathrm{TiO}_{2}$ nanostructures was about $1.5 \mathrm{~nm}$.

\subsection{Supported osmium nanoparticles}

As another PGM nanostructures, osmium nanoparticles are often supported on various carbon nanomaterials. For example, Kavitha et al. deposited Os nanoparticles on the surface of reduced graphene oxide ${ }^{68}$ carrying out a reduction process with the phase transfer of the osmium precursor (briefly: $\mathrm{OsCl}_{3}$ transferred to the toluene phase using tetraoctylammonium bromide was mixed with an aqueous suspension of graphene oxide prepared by the Hummers' method, then hydrazine was added and the system was heated to $90{ }^{\circ} \mathrm{C}$ for 90 minutes). TEM analysis showed that the size of formed Os nanoparticles was 2$3 \mathrm{~nm} .^{68}$ The Os nanoparticles was also deposited on carbon nanotubes. ${ }^{69}$ At first, the metalorganic Os precursor $\left[\mathrm{Os}_{3}(-\right.$ $\left.\mathrm{CO})_{10}\left(\mathrm{NCCH}_{3}\right)_{2}\right]$ was dissolved in acetone and sonicated. Then, the solvent was evaporated under $\mathrm{N}_{2}$ stream in a pyrolysis tube. Subsequently, the tube was sealed and heated to $400{ }^{\circ} \mathrm{C}$ under vacuum $\left(10^{-6}\right.$ bar $)$ in furnace for 12 hours. The as synthesized Os nanoparticles were supported on carbon nanotubes by the chemical vapor deposition. TEM analysis revealed formation of $2 \mathrm{~nm}$ Os nanoparticles attached to the surface of carbon nanotubes. Electron diffraction measurements showed, that the formed Os nanoparticles has a polycrystalline nature.

Low et al. synthesized osmium nanoparticles dispersed on silica. ${ }^{70}$ For this purpose, pentane was added to a flask containing dehydroxylated silica and subsequently osmium(cyclooctadiene)(cyclooctatetraene) was introduced to the flask. Then pentane was removed under reduced pressure. The addition and removal of pentane was repeated three times to achieve a good dispersion of osmium precursor on the surface of silica. After that, the silica with the adsorbed Os precursor was dried under vacuum and subsequently loaded to a glass reactor filled with $\mathrm{H}_{2}$ at the pressure of 0.66 bar, heated to $300{ }^{\circ} \mathrm{C}$ and kept at this temperature for 16 hours.

Using silica structures as sacrificial templates Molefe and coworkers formed Os nanoparticles trapped into a hollow carbon spheres. ${ }^{71}$ At first, the $\mathrm{SiO}_{2}$ microspheres were synthesized by a modified Stober method. Subsequently, obtained $\mathrm{SiO}_{2}$ structures was mixed with ethanol, urea and $\left(\mathrm{NH}_{4}\right)_{2} \mathrm{OsCl}_{6}$ (as a osmium precursor) and sonicated until formation of uniform suspension. After homogenization, the obtained material was heated to $95{ }^{\circ} \mathrm{C}$ and kept at this temperature for 12 hours. This step leads to the formation of Os nanoparticles supported on the surface of $\mathrm{SiO}_{2}$ microspheres. Then, the carbon layer was formed by a chemical vapor deposition at $950{ }^{\circ} \mathrm{C}$ for 2 hours using toluene as a carbon source. The product formed at this stage can be described as $\mathrm{SiO}_{2} @ O$ s/C nanoparticles. Finally, the 
$\mathrm{SiO}_{2}$ cores were etched by $\mathrm{HF}$ to form Os nanoparticles encapsulated inside hollow carbon nanospheres.

Osmium nanoparticles have been also deposited on the surface of zeolite $\mathrm{Y} .{ }^{72}$ For this purpose, zeolite $\mathrm{Y}$ was mixed with an aqueous solution of $\mathrm{OsCl}_{3}$. After $72 \mathrm{~h}$, the initially opaquebrown supernatant turned colorless due to the complete ion exchange - osmium ions were introduced into the surface of zeolite $\mathrm{Y}$ by the ions exchange reaction. Then $\mathrm{Os}^{3+}$ ions were reduced by sodium borohydride. TEM analysis showed that the average diameter of formed Os nanoparticles was $3.2 \pm 0.9 \mathrm{~nm}^{72}$

\section{Selected applications of Ru, Rh, Ir and Os nanoparticles in catalysis}

PGMs have many very useful properties and therefore they have many various important applications (for example, in production of: electrical contacts, electronic elements, thermocouples, alloys with special properties - e.g. for dentistry, elements of jewelry, filters in some X-rays devices, anticancer drugs, etc.). However, without any doubts, the most important group of applications of nanoparticles of PGMs is heterogeneous catalysis. Below we present some selected examples of applications of $\mathrm{Ru}, \mathrm{Rh}$, Ir and Os nanoparticles in catalysis. Due to very large number of publications on the catalytic applications of $\mathrm{Ru}, \mathrm{Rh}$, Ir, and Os nanoparticles, we discuss only a small part of the available literature, mainly those works that show a change in the catalytic activity of such nanoparticles caused by a change in the method of their synthesis.

\subsection{CO oxidation}

Very important use of PGMs is in catalytic converters in automobiles, which are used for transferring harmful carbon monoxide, nitrogen oxides and unburned hydrocarbons exhaust emissions into less noxious gases. Therefore, the description of the catalytic applications of nanoparticles formed from less commonly used members of the platinum family will be started from the presentation of some their applications as catalyst for $\mathrm{CO}$ oxidation.

In our opinion, for PGMs, the most interesting mechanism of the catalytic oxidation of $\mathrm{CO}$ to $\mathrm{CO}_{2}$ is observed on ruthenium. Moreover, the catalytic activity of $\mathrm{Ru}$ nanoparticles strongly depends on their size and structure, and therefore depends on the method of their preparation. Hence, as an example of the application of $\mathrm{Ru} / \mathrm{Rh} / \mathrm{Ir} / \mathrm{Os}$ nanoparticles in $\mathrm{CO}$ oxidation, we will describe some results concerning CO oxidation over Ru nanoparticles. Since the catalytic oxidation of $\mathrm{CO}$ over PGMs is very widely studied and is described in numerous publications, interested readers are referred to the more specialized review articles. ${ }^{73-75}$

Oxidation of $\mathrm{CO}$ over Ru nanoparticles has been studied, for example, by Joo et al. $^{2}$ In this case, Ru nanoparticles were supported on silica wafers and the catalytic reaction was carried out using a chamber filled with a $\mathrm{CO} / \mathrm{O}_{2} / \mathrm{He}$ mixture within a temperature range from 180 to $240{ }^{\circ} \mathrm{C}$. Fig. 5a shows the turnover frequency (TOF) for the $\mathrm{CO}$ to $\mathrm{CO}_{2}$ oxidation at various temperatures over $\mathrm{Ru}$ nanoparticles having different size, and
Fig. 5b shows the turnover frequency and the activation energy $\left(E_{\mathrm{a}}\right)$ of this process at $240{ }^{\circ} \mathrm{C}$ over $\mathrm{Ru}$ nanoparticles having different size. ${ }^{2}$ These experiments showed that at $240{ }^{\circ} \mathrm{C}$, the catalyst based on $6 \mathrm{~nm}$ Ru nanoparticles exhibits 8-fold higher catalytic activity than that based on $2.1 \mathrm{~nm}$ Ru nanoparticles. ${ }^{2}$ The potential reason of this effect is connected with the fact, that in a case of oxidizing conditions, the surface of metallic ruthenium is at first converted to a catalytically active thin ruthenium oxide layer $\left(\mathrm{Ru}_{2} \mathrm{O}\right)$ which subsequently transforms into an inactive oxide phase. ${ }^{76}$ Interactions of the ruthenium nanoparticles with a substrate significantly decrease the stability of this catalytically active thin ruthenium oxide layer, whereas increase in the size of the ruthenium nanoparticles increases stability of this film.

Kusada et al. synthesized Ru nanoparticles with hcp (a standard structure of a bulk ruthenium) and fcc crystallographic structures and compared their catalytic activity towards oxidation of $\mathrm{CO}$ (see Fig. $5 \mathrm{c}$ ). ${ }^{4}$ The $\mathrm{CO}$ oxidation was carried out in a tubular quartz reactor containing a gas mixture composed of $\mathrm{CO} / \mathrm{O}_{2} / \mathrm{He}$. The catalyst was heated to $100{ }^{\circ} \mathrm{C}$ and after 15 minutes, the eluent gas was collected and was analyzed by gas chromatography. It was found, that for hcp Ru nanoparticles, the temperature for $50 \%$ conversion of $\mathrm{CO}$ to $\mathrm{CO}_{2}\left(T_{50}\right)$ increases with increasing the particle size (see Fig. 5c), a trend similar to that observed for Au or Rh nanoparticles. ${ }^{20,77}$ However, different situation is observed for fcc $\mathrm{Ru}$ nanoparticles, when $T_{50}$ decreases with increasing the particle size (see Fig. 5c), a similar to the trend observed for Pt nanoparticles. ${ }^{78}$ As mentioned above, some reports revealed that $\mathrm{CO}$ oxidation on hcp $\mathrm{Ru}$ nanoparticles begins from oxidation of $\mathrm{Ru}(001)$ to a $\mathrm{RuO}_{2}(110)$ layer, and a subsequent $\mathrm{CO}$ oxidation occurs on $\mathrm{RuO}_{2}(110)$. In a case of fcc Ru nanoparticles, the dominant facet is (111), which has the lowest surface energy. It means that the surface of fcc Ru should exhibit higher reactivity than the surface of hcp Ru. Additionally, the higher catalytic activity of fcc Ru nanoparticles (it means having another structure than a bulk metal) may be attributed in part to a higher number of defects in such structures, such as twin boundaries.

\subsection{Fischer-Tropsch synthesis}

Another example of an economically important process which can be carried out using PGMs nanoparticles (ruthenium catalysts seem to be the most active ones) and which shows strong dependence on the structure of used catalytic nanostructures is a Fischer-Tropsch synthesis (FTS). The FTS is a class of chemical reactions that converts a mixture of $\mathrm{CO}$ and $\mathrm{H}_{2}$ into hydrocarbons. The FTS occurs at $150-350{ }^{\circ} \mathrm{C}$ through polymerization of $\mathrm{CH}_{x}$ building blocks generated from syngas by the $\mathrm{CO}$ dissociation followed by the $\mathrm{C}$ hydrogenation. The main products of FTS are paraffin, ${ }^{79}$ waxes $^{80}$ and small amounts of oxygenates like alcohols, acids, esters, ketones and aldehydes. ${ }^{81}$

It was found that the size of used ruthenium nanoparticles significantly effects the composition of the product of the FTS process. ${ }^{82}$ The larger Ru nanoparticles supported on $\mathrm{TiO}_{2}$ have improved reduction properties which leads to the preference of 

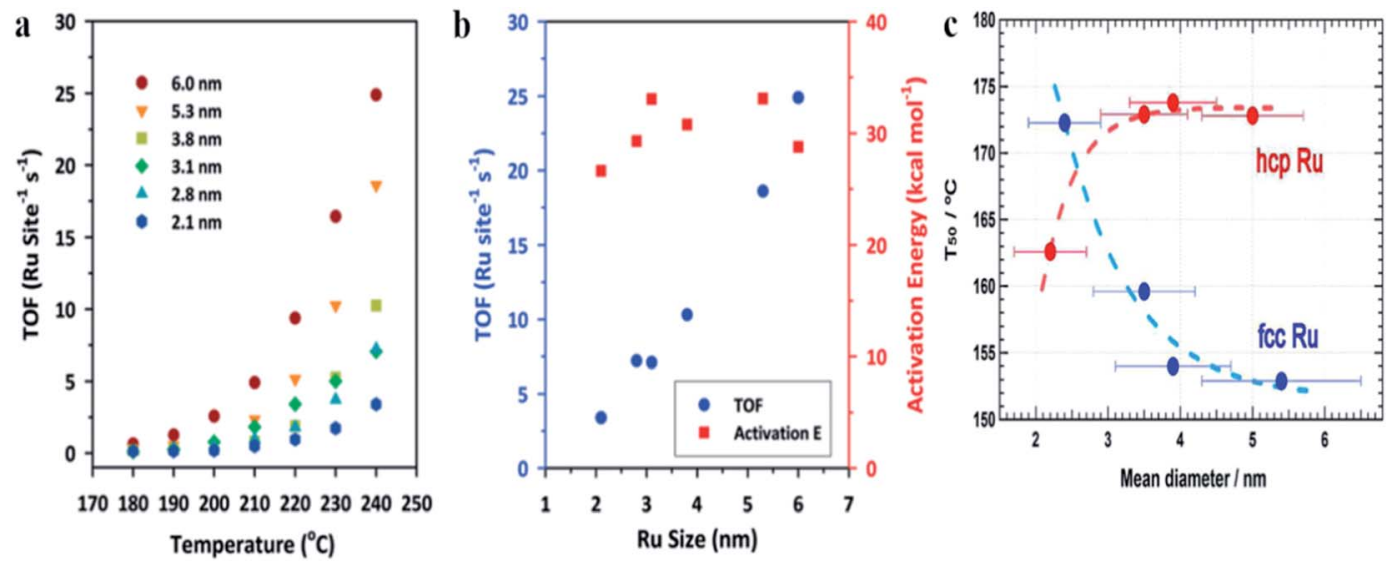

Fig. 5 (a) The turnover frequency (TOF) for the $\mathrm{CO}$ to $\mathrm{CO}_{2}$ oxidation at various temperatures over Ru nanoparticles having different size. (b) The turnover frequency (TOF) for the $\mathrm{CO}$ to $\mathrm{CO}_{2}$ oxidation and the activation energy $\left(E_{\mathrm{a}}\right)$ of this process at $240{ }^{\circ} \mathrm{C}$ over Ru nanoparticles having different size. (c) The temperature for $50 \%$ conversion of $\mathrm{CO}$ to $\mathrm{CO}_{2}\left(T_{50}\right)$ over fcc and hcp Ru nanoparticles having different size. (a) and (b) Reprinted with permission from ref. 2. Copyright 2010 the American Chemical Society. (c) Reprinted with permission from ref. 4. Copyright 2013 the American Chemical Society.

methanation, while smaller Ru nanoparticles are less effective in reduction which promotes the chain growth.

Another important factor affecting on the composition of the products of FTS is a pore size of the support material. ${ }^{83}$ It was found that the $\mathrm{CO}$ conversion and the selectivity towards $\mathrm{C}_{5+}$ hydrocarbons increase with increasing pore size, whereas the ethane selectivity shows an opposite trend.

Using osmium nanoparticles (instead of ruthenium) on various supports (e.g. $\mathrm{SiO}_{2},{ }^{71} \mathrm{Al}_{2} \mathrm{O}_{3},{ }^{84}$ and carbon spheres ${ }^{71}$ ) leads to formation in the FTS of practically only $\mathrm{C}_{1}$ and $\mathrm{C}_{2}$ hydrocarbons and no long chain hydrocarbons are formed.

\subsection{Decomposition of nitrogen oxides}

Nitrogen oxides $\left(\mathrm{NO}_{x}\right)$ generated by industry and by the internal combustion engines in various vehicles are very important air pollutants. Decomposition of $\mathrm{NO}_{x}$ is effectively catalyzed by many types of materials, such as: zeolites, metal oxides and PGMs. ${ }^{85}$ The generally accepted mechanism of NO decomposition in a presence of PGMs catalysts involves adsorption of molecules of NO on the metal surface, NO dissociation leading to $\mathrm{N}$ and $\mathrm{O}$ atoms adsorbed on the metal surface, and recombination of the adsorbed atoms leading to the formation of molecules of $\mathrm{N}_{2}$ and $\mathrm{O}_{2} \cdot \mathrm{N}_{2}$ desorbs easily from the surface of PGMs even in relatively low temperatures (e.g. $\left.190{ }^{\circ} \mathrm{C}\right),{ }^{86}$ but desorption of $\mathrm{O}_{2}$ is significantly more difficult and low efficiency of this process may even lead to a deactivation of the catalyst. $^{87,88}$ Hence, many groups are working on increasing the effectiveness of $\mathrm{O}_{2}$ desorption from PGMs. Rhodium is preferable to other PGMs in the nitrogen oxides decomposition and therefore nowadays, the majority of rhodium consumed worldwide is used in automobiles in catalytic converters.

As an example of the rhodium catalyst for NO conversion, one can mention rhodium nanoparticles deposited on carbon nanotubes which, at $400{ }^{\circ} \mathrm{C}$, convert $\mathrm{NO}$ into $\mathrm{N}_{2}, \mathrm{O}_{2}$ and $\mathrm{N}_{2} \mathrm{O}$ with almost $100 \%$ efficiency - decrease in the temperature leads to decrease in the efficiency of the NO conversion. ${ }^{89}$ Interestingly, this catalyst allows for the production of a significant amounts of $\mathrm{N}_{2} \mathrm{O}-$ at $300{ }^{\circ} \mathrm{C}$ the efficiency of the transformation to $\mathrm{N}_{2} \mathrm{O}$ reaches $55 \% .{ }^{89}$ Beyer et al. also investigated this system (rhodium nanoparticles on carbon nanotubes) and reported that the conversion rate of NO reaches a maximum (99\%) at $400{ }^{\circ} \mathrm{C}$, with the selectivity towards $\mathrm{N}_{2}$ equal to about $94 \% .{ }^{90}$ Vermisoglou et al. showed that for Rh nanoparticles supported on single-wall carbon nanotubes functionalized with PEG, an efficient oxygen desorption is observed at a temperature as low as $110{ }^{\circ} \mathrm{C} .{ }^{91}$ What more, in a presence of $\mathrm{CO}$ as a reducing agent, the catalyst retained high activity for more than $24 \mathrm{~h}$ on stream with intermediate steps of regeneration in helium atmosphere every $4.5 \mathrm{~h}$. This catalyst exhibits good selectivity towards $\mathrm{N}_{2}$ formation (about 76-96\%). ${ }^{91}$

In many cases catalysts containing mixtures of rhodium and another metal (or metals) from the platinum group are used. For example, Salker and Desai investigated $\mathrm{M}_{0.05} \mathrm{Co}_{2.95} \mathrm{O}_{4}$ structures containing $\mathrm{Rh}, \mathrm{Ru}$ and $\mathrm{Pd}$ (where $\mathrm{M}$ is used to denote $\mathrm{Rh}$ and $\mathrm{Ru}$ and $\mathrm{Pd}) .{ }^{92}$ In the temperature range between 300 and $400{ }^{\circ} \mathrm{C}$, the efficiency of the NO conversion over pure $\mathrm{Co}_{3} \mathrm{O}_{4}$ is about $40 \% .{ }^{92}$ Above this temperature the yield drops. ${ }^{92}$ The addition of PGMs increases the efficiency of the catalytic reaction even in the temperature range between 200 and $300{ }^{\circ} \mathrm{C}$. The rhodium-doped catalyst allows for even $100 \%$ conversion of NO. In a case of admixtures with ruthenium, the conversion rate was lower (about 70\%), however, the stability of the catalyst and the selectivity of reduction to $\mathrm{N}_{2}$ instead of $\mathrm{N}_{2} \mathrm{O}$ is increased. ${ }^{92}$

Not only rhodium and its alloys has been used as PGMs catalysts for NO decomposition. For example, Baudin et al. synthetized $\mathrm{Ir} / \mathrm{Ce}_{0.6} \mathrm{Zr}_{0.4} \mathrm{O}_{2}$ catalyst and showed that at about $250{ }^{\circ} \mathrm{C}$, the 1-propanol assisted-reduction of $\mathrm{NO}_{x}$ reaches over this catalyst almost $100 \%$ efficiency. ${ }^{93}$

It was found that the catalytic activity of bimetallic nanoparticles can be significantly higher than those of standard one 
element structures. For example, the bimetallic $\mathrm{Ru}-\mathrm{Ir} / \mathrm{TiO}_{2}$ (9:1) catalyst exhibits more than two times higher activity towards removal of $\mathrm{NO}_{x}$ than the one element $\mathrm{Ru} / \mathrm{TiO}_{2}$ and $\mathrm{Ir} /$ $\mathrm{TiO}_{2}$ catalysts. ${ }^{94} \mathrm{Ir}-\mathrm{Ru}$ nanoparticles have been also supported on $\mathrm{Al}_{2} \mathrm{O}_{3} \cdot{ }^{95}$ This catalyst exhibits high $\mathrm{NO}_{x}$ conversion rate (91\%) which could be achieved at $175^{\circ} \mathrm{C}$, while the monometallic $\mathrm{Ru}$ and Ir catalysts have no activity in $\mathrm{NO}_{x}$-decomposition at this temperature.

Another example of alloy nanoparticles from PGMs that have a significant activity in $\mathrm{NO}$ decomposition are $\mathrm{Pd}_{0.5} \mathrm{Ru}_{0.5}$ nanostructures. Sato et al. showed that the degree of $\mathrm{NO}_{x}$ to $\mathrm{N}_{2}$ conversion over these nanostructures reaches almost 100\% already at a temperature of about $200{ }^{\circ} \mathrm{C}$ (the tests were carried out using a gas derived from gasoline combustion). ${ }^{\mathbf{9 6}}$ For comparison, platinum nanoparticles achieves a similar degree of conversion in a significantly higher temperature (at about 350 $\left.{ }^{\circ} \mathrm{C}\right)$. It should be noted that the obtained $\mathrm{Pd}_{0.5} \mathrm{Ru}_{0.5}$ structures reveal a similar efficiency of the catalytic NO decomposition as rhodium nanoparticles (the most efficient PGMs catalyst of this process).

\subsection{Hydrogenation processes}

PGMs nanoparticles are often used as catalysts in various hydrogenation processes. For example, Esteban et al. carried out hydrogenation of benzene and cyclohexene using iridium nanoparticles supported on a reduced graphene oxide. ${ }^{97}$ With this catalyst benzene hydrogenation was possible at $100{ }^{\circ} \mathrm{C}$ and under 10 bar of $\mathrm{H}_{2}$. Esteban et al. found that the iridium nanoparticles with a diameter of $3.6 \pm 1.0 \mathrm{~nm}$ have the highest catalytic activity, whereas bigger and smaller Ir nanoparticles are significantly less active. ${ }^{97}$ Hydrogenation of various substituted benzenes can be also carried out using as a catalyst rhodium nanoparticles supported on carbon nanofibers. ${ }^{56}$ Motoyama et al. found that for such systems, the catalytic activity strongly depends on the structure of the support, it means, on the arrangement of the graphite layers in carbon nanofibers: the highest activity was observed in a case of the tubular arrangement, lower for the platelet arrangement and the lowest activity for the herringbone arrangement. ${ }^{56}$ Interestingly, when the same group studied the process of hydrogenation of nitroarenes on $\mathrm{Pt}$ nanoparticles deposited on carbon nanofibers, they observed reverse influence of the arrangement of the graphite layers on the activity of the catalyst. ${ }^{98}$

Pan and Wai studied influence of the size of rhodium nanoparticles supported on carbon nanotubes on their catalytic activity in the hydrogenation of $o^{-}, m^{\text {- }}$ and $p$-xylenes. ${ }^{99}$ Hydrogenation of xylenes was carried out in liquid arenes without addition of any other solvent to avoid solvent effects. Pan and Wai found that the hydrogenation rate reveals a negative particle size effect. ${ }^{99}$ Hydrogenation of xylenes can occur in two different ways leading to trans or cis dimethylcyclohexane. Formation of trans isomer is thermodynamically preferable. Pan and Wai also found that even the cis-trans ratio in the obtained product depends on the size of rhodium nanoparticles that are used as a catalyst - decreasing the size of $\mathrm{Rh}$ nanoparticles leads to increase in the cis-trans ratio. ${ }^{99}$ Another investigations showed that not only size, but also the shape of rhodium nanoparticles could affected on their catalytic activity in the hydrogenation of arenes. ${ }^{\mathbf{1 0 0}}$ For example, the $4.9 \pm 0.4 \mathrm{~nm}$ tetrahedral rhodium nanoparticles supported on charcoal exhibit 109 times higher catalytic activity than the $4.8 \pm 0.4 \mathrm{~nm}$ spherical rhodium nanoparticles supported on charcoal and 5.8 times higher catalytic activity than the commercial $\mathrm{Rh} / \mathrm{C}$ catalyst. ${ }^{100}$ Jacinto et al. showed that one can easily improve reusability of the catalyst Rh nanoparticles by immobilization of such nanostructures on amino-modified silica-coated magnetic nanoparticles. ${ }^{\mathbf{5 8}}$ $\mathrm{Rh}$ nanoparticles immobilized on magnetic supports can be easily efficiently recovered from the reaction medium by applying an external magnetic field - Jacinto et al. showed that such very simple method of separation allows for using this catalyst up to 20 time without a significant loss in its catalytic activity.

Cyclohexene and phenylacetylene can be hydrogenated in a methanolic solution under mild condition in a presence of iridium nanoparticles deposited on microporous sodalite-like zeolitic imidazole framework as a catalyst. ${ }^{\mathbf{1 0 1}}$ Zahmakiran showed that also in this case the catalytic activity of Ir nanoparticles depends on their average size - the highest activity was observed for the smallest nanoparticles. ${ }^{\mathbf{1 0 1}}$

\subsection{Conversion of $\mathrm{CO}_{2}$}

It is well known that increasing $\mathrm{CO}_{2}$ amount in the atmosphere leads to a climate change and a global warming. Therefore, in recent years, conversion of $\mathrm{CO}_{2}$ into hydrocarbons or other organic compounds is a major research focus of many groups. Reduction of $\mathrm{CO}_{2}$ by $\mathrm{H}_{2}$ has been analyzed, for example, by Kwak et al. ${ }^{\mathbf{1 0 2}}$ This group performed their studies using a series of $\mathrm{Ru} / \mathrm{Al}_{2} \mathrm{O}_{3}$ catalysts with ruthenium content in the $0.1-5 \%$ range, and they found that with increasing metal loading, the selectivity toward formation of $\mathrm{CH}_{4}$ increases, while that for the CO production decreases (see Fig. 6). ${ }^{\mathbf{1 0 2}}$ Kwak et al. explained observed change of the reaction pathway by the clustering of a highly dispersed metal phase and formation of active centers of a different nature. ${ }^{\mathbf{1 0 2}}$ On the other hand, Aitbekova et al. found that more active for $\mathrm{CO}_{2}$ methanation are smaller Ru nanoparticles. ${ }^{103}$ This group also showed that a type of a support strongly effects on the selectivity of the $\mathrm{CO}_{2}$ catalytic reduction. ${ }^{103}$ The highest selectivity for the $\mathrm{CO}$ production is observed when $\mathrm{Ru}$ nanoparticles are supported on $\mathrm{CeO}_{2}$, slightly lower selectivity occurs in a case of using $\mathrm{TiO}_{2}$ support, while the lowest is observed for $\mathrm{Al}_{2} \mathrm{O}_{3}$ support. ${ }^{103}$

The crystal phase effects of the substrate was also studied by Lin and co-workers for $\mathrm{CO}_{2}$ methanation catalyzed by $\mathrm{Ru}$ nanoparticles deposited on $\mathrm{TiO}_{2}{ }^{104}$ In these studies, ruthenium nanoparticles were formed by a wet impregnation (impregnation of a support with a precursor-containing solution and drying) on two types of $\mathrm{TiO}_{2}$ surface: the rutile-type $\mathrm{TiO}_{2}\left(\mathrm{r}-\mathrm{TiO}_{2}\right)$ and the anatase-type $\mathrm{TiO}_{2}\left(\mathrm{a}-\mathrm{TiO}{ }_{2}\right) .{ }^{104} \mathrm{TEM}$ analysis showed, that the average size of $\mathrm{Ru}$ nanoparticles formed 

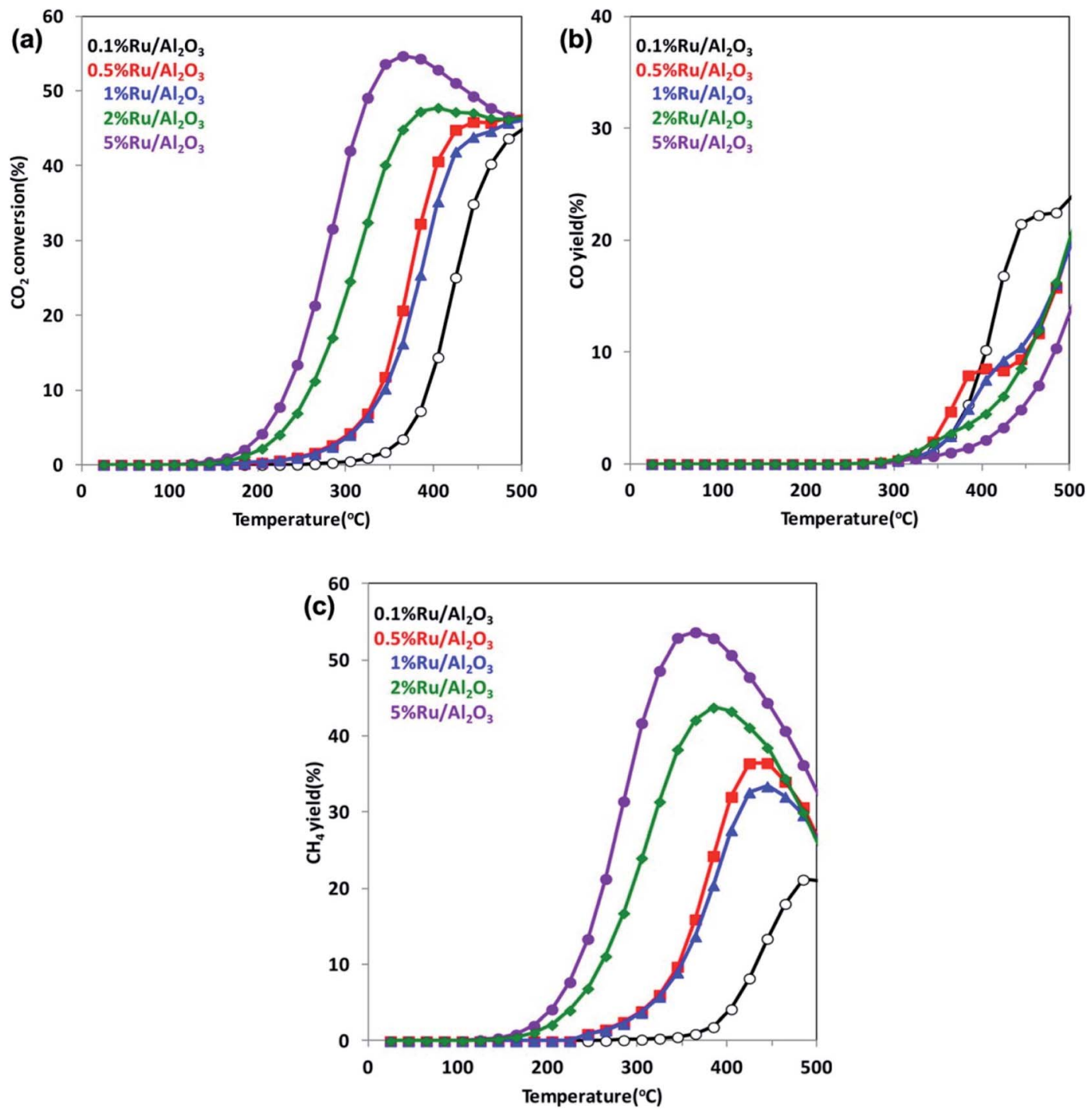

Fig. 6 (a) Temperature dependences of the $\mathrm{CO}_{2}$ conversion rate over $\mathrm{Ru} / \mathrm{Al}_{2} \mathrm{O}_{3}$ catalysts for various Ru loadings. (b) and (c) Temperature dependences of the yields of the formation of $\mathrm{CO}$ and $\mathrm{CH}_{4}$, respectively, over $\mathrm{Ru} / \mathrm{Al}_{2} \mathrm{O}_{3}$ catalysts for various Ru loadings. Reprinted with permission from ref. 102. Copyright 2013 the American Chemical Society.

on the surface of $\mathrm{r}-\mathrm{TiO}_{2}$ is $1.1 \pm 0.2 \mathrm{~nm}$, while in a case of formation of $\mathrm{Ru}$ nanoparticles on the surface of $\mathrm{r}-\mathrm{TiO}_{2}$, the obtained nanoparticles were significantly larger and had the average size of $4.0 \pm 2.4 \mathrm{~nm}$. Results of the catalytic tests showed, that the $\mathrm{Ru} / \mathrm{r}-\mathrm{TiO}_{2}$ nanoparticles exhibit a much higher activity and thermal stability in $\mathrm{CO}_{2}$ methanation than the $\mathrm{Ru} / \mathrm{a}-\mathrm{TiO}_{2}$ nanostructures. ${ }^{104}$ A significant substrate effect on the conversion of $\mathrm{CO}_{2}$ on the supported $\mathrm{Ru}$ nanoparticles was also observed by Wang and co-workers. ${ }^{105}$ This group analyzed conversion of $\mathrm{CO}_{2}$ catalyzed by the $\mathrm{Ru}$ nanoparticles supported on $\mathrm{CeO}_{2}$ and $\mathrm{Al}_{2} \mathrm{O}_{3}$. It was found that the reaction route depends on a type of a support. In a case of a $\mathrm{CeO}_{2}$ support, the main product is $\mathrm{CH}_{4}$, while in a case of a $\mathrm{Al}_{2} \mathrm{O}_{3}$ support the dominant product is $\mathrm{CO} .^{105}$

Reduction of $\mathrm{CO}_{2}$ was also carried out using as a catalyst iridium nanoparticles supported on $\mathrm{CeO}_{2} \cdot{ }^{106}$ It was found that also in this case a size of metal nanoparticles plays a crucial role in the reduction process. For example, when the size of Ir nanoparticles dropped from 2.5 to $1 \mathrm{~nm}$, there was no methane in the products and the selectivity toward formation of $\mathrm{CO}$ was $100 \%$. The potential reason of this effect is a fact that with the decreasing size of Ir nanoparticles more oxygen atoms is incorporated into the metal what changes the chemical properties of Ir nanoparticles and therefore their catalytic performance.

\subsection{Reduction reactions}

Aromatic nitro compounds are widely applied in industry. The reduction of nitro compounds is an important method for preparation of aniline and its derivatives. Traditionally, the reduction of nitro compounds is carried out in a presence of $\mathrm{Fe} / \mathrm{HCl}$. However, this method leads to formation of a large amount of waste what is not environmentally friendly. 
Therefore, a development of novel highly efficient and selective catalysts towards reduction of nitro compounds is highly desirable.

Very promising catalysts for this process are rhodium nanoparticles (often supported). ${ }^{\mathbf{1 0 7 - 1 1 1}}$ It is worth mentioning that the reduction of nitro compounds can be often easily monitored by simple UV-Vis absorption measurements. For example, in a case of reduction of 4-nitrophenol, an initial solution of 4-nitrophenol exhibits pale yellow color (the absorption band at $316 \mathrm{~nm}$ ). After reduction, the solution fades to colorless, due to the formation of 4-aminophenol with the absorption band at $303 \mathrm{~nm} .{ }^{\mathbf{1 0 7}}$ The catalytic activity and selectivity of some PGMs nanoparticles towards reduction of various aromatic compounds are shown in Table 2.

\subsection{Hydrogen generation from various compounds used for hydrogen storage}

Currently due to increase in the $\mathrm{CO}_{2}$ emission and hence global warming and climatic changes, new compounds used to "storage energy" that do not generate $\mathrm{CO}_{2}$ during their conversion into an "energy" are developed. One of them is hydrogen. Important problem in a case of hydrogen is its storage. A very promising method of hydrogen storage is its storage in various chemical compounds, for example, ammonia borane $\left(\mathrm{NH}_{3} \mathrm{BH}_{3}\right)$. The hydrogen stored in $\mathrm{NH}_{3} \mathrm{BH}_{3}$ could be released in various ways, but the hydrolytic dehydrogenation of $\mathrm{NH}_{3} \mathrm{BH}_{3}$ seems to be the most promising one:

$$
\mathrm{NH}_{3} \mathrm{BH}_{3(\mathrm{aq})}+2 \mathrm{H}_{2} \mathrm{O} \stackrel{\text { cat }}{\rightarrow} \mathrm{NH}_{4} \mathrm{BO}_{2}+3 \mathrm{H}_{2}
$$

It was found that nanoparticles of PGMs can be used as highly efficient catalysts towards hydrolysis of $\mathrm{NH}_{3} \mathrm{BH}_{3}$ (see
Table 3). For example, a very promising catalyst of this reaction is ruthenium in a form of either unsupported nanoparticles ${ }^{\mathbf{1 0}}$ or nanoparticles supported on various substrates: graphene, ${ }^{47} \gamma$ $\mathrm{Al}_{2} \mathrm{O}_{3},{ }^{7}$ or silica nanospheres. ${ }^{112}$ Using Ru catalysts hydrolysis of $\mathrm{NH}_{3} \mathrm{BH}_{3}$ be carried out at room temperature and in some cases it takes only a few minutes to finalize this process (for more details how various parameters influence this process see Fig. 7).

Hydrolysis of $\mathrm{NH}_{3} \mathrm{BH}_{3}$ can be also carried using both unsupported rhodium nanoparticles ${ }^{\mathbf{1 1 3}}$ and rhodium nanoparticles deposited on carbon black, ${ }^{54}$ carbon nanotubes, ${ }^{\mathbf{1 1 4}}$ graphitic carbon nitride, ${ }^{115}$ and various oxides, such as: $\mathrm{Al}_{2} \mathrm{O}_{3}$, $\mathrm{SiO}_{2}, \mathrm{TiO}_{2}, \mathrm{HfO}_{2}$ and $\mathrm{CeO}_{2} \cdot{ }^{57}$ Chen and co-workers found that smaller Rh nanoparticles exhibit better catalytic activity than the bigger ones. ${ }^{54}$ Also the material of the support influences on the catalytic activity of rhodium nanoparticles, for example, the activity of Rh nanoparticles deposited on $\mathrm{CeO}_{2}$ is higher than the activity of $\mathrm{Rh}$ nanoparticles deposited on $\mathrm{Al}_{2} \mathrm{O}_{3}, \mathrm{SiO}_{2}, \mathrm{TiO}_{2}$, and $\mathrm{HfO}_{2}{ }^{57}$

Hydrogen can be also produced from ammonia borane by the following reaction with methanol:

$$
\mathrm{NH}_{3} \mathrm{BH}_{3(\mathrm{sol})}+4 \mathrm{CH}_{3} \mathrm{OH} \stackrel{\text { cat }}{\rightarrow} \mathrm{NH}_{4} \mathrm{~B}\left(\mathrm{OCH}_{3}\right)_{4}+3 \mathrm{H}_{2}
$$

This process is also effectively catalyzed by rhodium nanoparticles supported on carbon ${ }^{\mathbf{1 1 6}}$ or on nanosilica ${ }^{\mathbf{1 1 7}}$ - when unsupported Rh nanoparticles are used, the turnover frequency is very low due to the aggregation of nanoparticles.

Another compound appearing to be a promising candidate for the chemical hydrogen storage is hydrazine borane. Similarly like in a case of ammonia borane, during hydrolysis of hydrazine borane a significant amount of hydrogen is formed.

Table 2 Catalytic activity (including turnover frequency (TOF), i.e., the number of moles of a substrate that a mole of catalyst can convert within 1 $\mathrm{min}$ ) and selectivity of nanoparticles of some PGMs towards reduction of various aromatic compounds

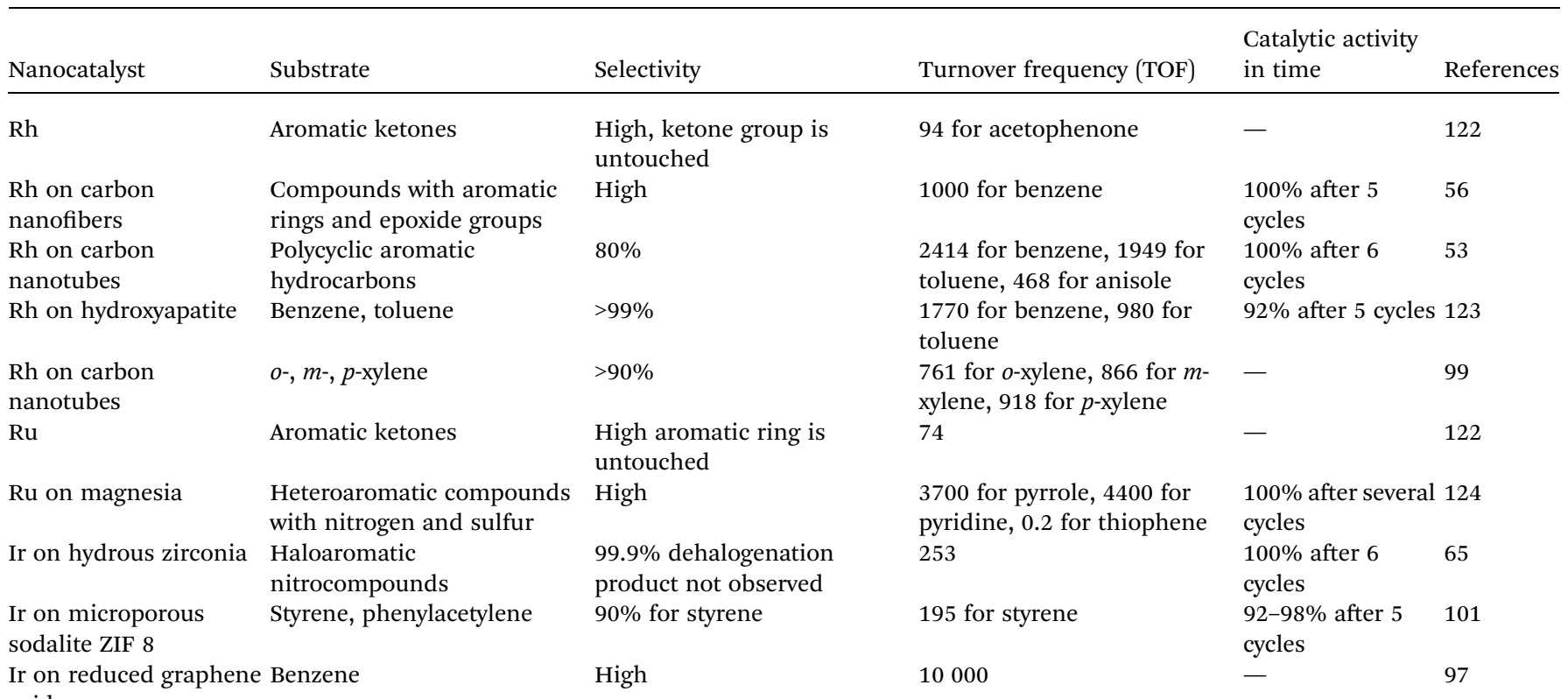


Table 3 Catalytic activity (including: activation energy $-E_{a}$ and turnover frequency - TOF, i.e., the number of moles of a substrate that a mole of catalyst can convert within $1 \mathrm{~min}$ ) and stability of some PGMs nanoparticles towards hydrolysis of ammonia borane

\begin{tabular}{|c|c|c|c|c|}
\hline $\mathrm{Rh}$ nanoclusters in zeolite & $66.9 \pm 1.3$ & 92 & Total turnover number: 47200 & 125 \\
\hline $\mathrm{Rh}$ on carbon black & 37.1 & 60 & $50 \%$ after 5 runs & 54 \\
\hline $\mathrm{Rh}$ on $\mathrm{WO}_{3-x}$ & 45.2 & 115 & $19.1 \%$ after 10 cycles & 127 \\
\hline $\mathrm{Rh}$ on $\mathrm{WO}_{3}$ & $39 \pm 2$ & 749 & $34 \%$ after 5 cycles & 128 \\
\hline $\mathrm{Rh}$ on graphene & 19.7 & 146 & $58 \%$ after 5 cycles & 129 \\
\hline $\mathrm{Rh}$ on $\mathrm{Co}_{3} \mathrm{O}_{4}$ & 63 & 1880 & - & 130 \\
\hline $\mathrm{Rh}$ on $\mathrm{Fe}_{3} \mathrm{O}_{4}$ & 57.5 & 272 & $100 \%$ after 5 cycles & 131 \\
\hline $\mathrm{Rh}$ on silica-coated $\mathrm{Fe}_{3} \mathrm{O}_{4}$ & $54 \pm 2$ & 17 & 5 cycles & 132 \\
\hline Rh on $\mathrm{TiO}_{2}$ & 47 & 643 & $57 \%$ after 5 cycles & 133 \\
\hline $\mathrm{Rh}$ on carbon & 37.1 & 336 & $50 \%$ after 5 cycles & 54 \\
\hline $\mathrm{Rh}$ on carbon nanotubes & $32 \pm 1$ & 706 & $61 \%$ after 5 cycles & 114 \\
\hline $\mathrm{Ru}-\mathrm{Rh}$ & $47.4 \pm 2$ & 386 & $68 \%$ after 5 cycles & 29 \\
\hline $\mathrm{Ru}$ & 27.5 & 21.8 & - & 10 \\
\hline Ru on nanodiamonds & 50.7 & 229 & $40 \%$ after 4 cycles & 136 \\
\hline Ru on MWCNTs & $33 \pm 2$ & 329 & $50 \%$ after 5 cycles & 137 \\
\hline Ru on MOF MIL53 & $28.9-33.7$ & $260.8-266.9$ & $71-75 \%$ after 5 cycles & 138 \\
\hline Ru on zeolite ZK-4 & & & & 139 \\
\hline $\mathrm{Ru}$ on $\mathrm{TiO}_{2}$ & $70 \pm 2$ & 241 & $90 \%$ after 3 cycles & 140 \\
\hline $\mathrm{Ru}$ on cubic mesoporous silica & 24.13 & 202 & - & 141 \\
\hline $\mathrm{Ru}$ on carbon black & 34.8 & 429.5 & $43.1 \%$ after 5 cycles & 142 \\
\hline $\mathrm{Ru}$ on $\mathrm{ZrO}_{2}$ & $58 \pm 2$ & 173 & $67 \%$ after 5 run & 143 \\
\hline $\mathrm{Ru}$ on $\mathrm{HfO}_{2}$ & 65 & 170 & $75 \%$ after 5 run & 144 \\
\hline Ru on MOF MIL96 & 48 & 231 & $65 \%$ after 5 run & 145 \\
\hline $\mathrm{Ru}$ on $\gamma-\mathrm{Al}_{2} \mathrm{O}_{3}$ & $48 \pm 21$ & 83.3 & $90 \%$ after 10 cycles & 7 \\
\hline $\mathrm{Ru}$ on $\mathrm{SiO}_{2}$ & 38.2 & 200 & - & 112 \\
\hline $\mathrm{Ru}$ on MWCNTs & 33 & 329 & Total turnover number: 26400 & 137 \\
\hline $\mathrm{Ru}$ on carbon & 76 & 113 & - & 150 \\
\hline $\mathrm{Ru}$ on $\gamma-\mathrm{Al}_{2} \mathrm{O}_{3}$ & 23 & 77 & - & 135 \\
\hline $\mathrm{Ru}$ on $\gamma-\mathrm{Al}_{2} \mathrm{O}_{3}$ & 67 & 23.05 & - & 152 \\
\hline $\mathrm{Ru}$ on $\gamma-\mathrm{C}_{3} \mathrm{~N}_{4}$ & 35.6 & 241 & $67.4 \%$ after 4 run & 153 \\
\hline $\mathrm{Ru}$ on cotton fibers & 32.41 & 322 & $80 \%$ after 5 runs & 154 \\
\hline
\end{tabular}

This reaction is effectively catalyzed by rhodium nanoparticles supported, for example, on hydroxyapatite. ${ }^{\mathbf{1 1 8}}$ Moreover, the hydrogen evolution at room temperature starts immediately after addition of the catalyst, without induction period, even when the concentration of Rh nanoparticles is low.

\subsection{Other reactions}

The catalytic applications of PGMs are numerous and in addition to the examples mentioned above, there are many other chemical reactions that can be catalyzed by PGMs. For example, osmium nanoparticles supported on the surface of zeolite $\mathrm{Y}$ exhibit high catalytic activity and selectivity towards aerobic oxidation of alcohols to carbonyl compounds. ${ }^{72}$ The same catalyst can be applied towards cis-dihydroxylation of olefins and acetylation of 1,2-cis-diols. ${ }^{119}$ Ruthenium nanoparticles supported on active carbon can be also used as a catalyst in aerobic oxidative cross-coupling between alcohols (e.g. benzyl alcohol) and amines (both aromatic, like aniline, and various acyclic and cyclic aliphatic ones) what leads to the formation of proper imines. ${ }^{120}$ Specific flat-shaped pristine fcc ruthenium nanoparticles having a large fraction of $\{111\}$ facets on their surfaces can be applied as a highly selective and reusable heterogeneous catalyst for the production of various primary amines by the reductive amination of carbonyl compounds. ${ }^{\mathbf{1 2 1}}$ 

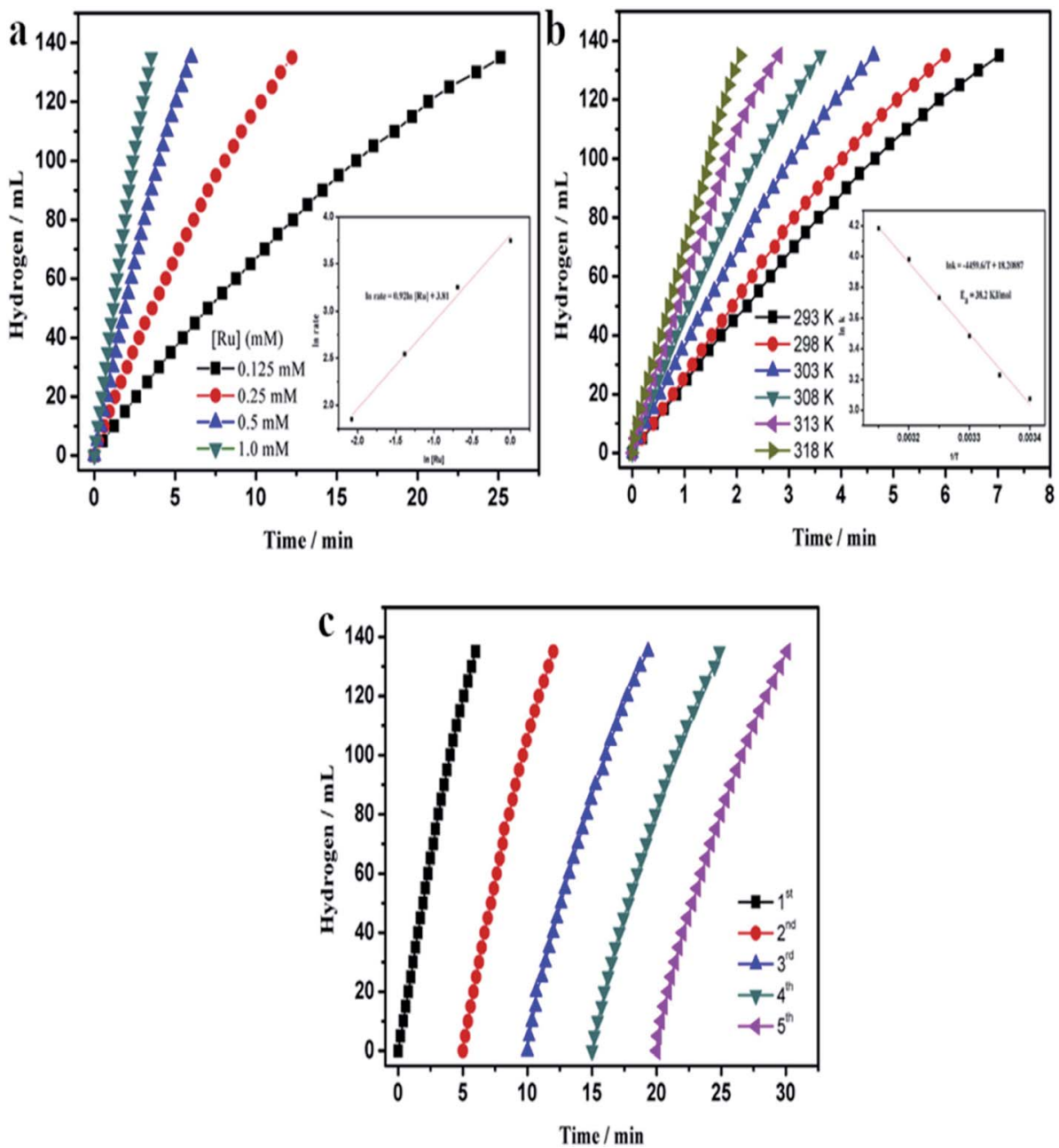

Fig. 7 Temporal dependences of the amount of hydrogen generated by the hydrolysis of a solution of ammonia borane (10 ml, $200 \mathrm{mM}$ ) reaction catalysed by Ru on silica nanospheres. (a) Dependences obtained for various concentrations of the Ru catalyst for the process carried out at $25^{\circ} \mathrm{C}$ (inset shows the hydrogen generation rate vs. Ru concentrations - both values are presented in a logarithmic scale). (b) Dependences obtained at various temperatures - inset shows the Arrhenius plot ( $\ln k$ vs. 1/T). (c) Dependences obtained for the subsequent runs of the process after addition of the same amount of ammonia borane. Reprinted with permission from ref. 112. Copyright 2014 the Elsevier.

Using this catalyst, amination reactions are realized with extremely high reaction rates at low temperatures. ${ }^{\mathbf{1 2 1}}$

\section{Conclusion and future outlook}

In this review article we described various methods of synthesis of nanoparticles from some platinum groups metal (PGMs). Due to very numerous literature concerning synthesis of Pt and Pd nanoparticles, in this work we focused only on synthesis of nanoparticles from less frequently used members of the platinum family (ruthenium, rhodium, osmium and iridium). Such nanoparticles can be obtained by many various processes using different metal precursors, solvents, reducing and stabilizing agents (for examples see Table 1). We showed that changing various factors like the temperature of the process, type of the metal precursor, type of the solvent, or concentration of the reagents, it is possible to control the size, geometry or even the crystallographic structure of the formed nanoparticles. In many cases nanoparticles of PGMs are supported on various substrates, that can also influence on their properties, mainly their catalytic activity. Obtained nanoparticles of PGMs are often used commercially as catalysts of many important reactions.

In the last part of this review article, we briefly present selected applications of nanoparticles of PGMs as catalysts - we mainly selected examples when the catalytic activity of such nanostructures depends on their size, shape and the crystallographic structure - it means examples, when the catalytic activity of nanoparticles clearly depends on the method of their synthesis. It shows how important is to improve methods of synthesis of PGMs nanoparticles to increase in the control of their size, shape, crystallographic structure and the homogeneity. We believe that unsupported and supported PGMs nanoparticles obtained according to recently developed procedures will replace many of the currently used commercial catalysts due to their improved catalytic activity and selectivity. 
Although this issue is not addressed in this review article, some future efforts should also focus on increasing the stability of unsupported and supported PGMs nanoparticles. Another problem is sometimes low recoverability of PGMs nanoparticles - an interesting possibility to increase reusability is the formation of composites from PGMs nanoparticles and magnetic nanostructures, and the concentration of PGMs from the reaction mixture using magnetic separation. PGMs are very expensive and any significant reduction in their consumption is very important from an economic point of view. Therefore, another likely modification of standard procedures for the preparation of commercial catalysts is the wider use of core-shell nanostructures, in which the precious PGMs only form the outermost layer of the system.

We hope that our work will convince readers that PGMs nanoparticles are fascinated subjects of research.

\section{Abbreviations}

$\begin{array}{ll}2,7-D H N & \text { 2,7-Dihydroxynapthalene } \\ \text { acac } & \text { Acetylacetonate } \\ \text { CTAB } & \text { Hexadecyltrimethylammonium bromide } \\ \text { DEG } & \text { Diethylene glycol } \\ \text { EG } & \text { Ethylene glycol } \\ \text { FTS } & \text { Fischer-Tropsch synthesis } \\ \text { MOF } & \text { Metal-organic framework } \\ \text { MWCNTs } & \text { Multi-walled carbon nanotubes } \\ \text { NC } & \text { Nitrogen-functionalized carbon } \\ \text { PEG } & \text { Polyethylene glycol } \\ \text { PGMs } & \text { Platinum-group metals } \\ \text { PVA } & \text { Polyvinyl acetate } \\ \text { PVP } & \text { Polyvinylpyrrolidone } \\ \text { SDS } & \text { Sodium dodecyl sulfate } \\ \text { TEM } & \text { Transmission electron microscopy } \\ \text { THF } & \text { Tetrahydrofuran } \\ \text { TrEG } & \text { Triethylene glycol } \\ \text { TTAB } & \text { Trimethyl(tetradecyl)ammonium bromide } \\ \text { UV } & \text { Ultraviolet } \\ \text { UV-Vis } & \text { Ultraviolet-visible } \\ \text { XRD } & \text { X-ray diffraction } \\ \end{array}$

\section{Conflicts of interest}

Authors declared that there is no conflict of interest regarding the publication of this paper.

\section{Acknowledgements}

This work has been financed by the University of Warsaw.

\section{References}

1 X. Yan, H. Liu and K. Y. Liew, J. Mater. Chem., 2001, 11, 3387-3391.

2 S. H. Joo, J. Y. Park, J. R. Renzas, D. R. Butcher, W. Huang and G. A. Somorjai, Nano Lett., 2010, 10, 2709-2713.
3 G. Viau, R. Brayner, L. Poul, N. Chakroune, E. Lacaze, F. Fiévet-Vincent and F. Fiévet, Chem. Mater., 2003, 15, 486-494.

4 K. Kusada, H. Kobayashi, T. Yamamoto, S. Matsumura, N. Sumi, K. Sato, K. Nagaoka, Y. Kubota and H. Kitagawa, J. Am. Chem. Soc., 2013, 135, 5493-5496.

5 Y. Yao, D. S. He, Y. Lin, X. Feng, X. Wang, P. Yin, X. Hong, G. Zhou, Y. Wu and Y. Li, Angew. Chem., Int. Ed., 2016, 55, 5501-5505.

6 H. Ye, Q. Wang, M. Catalano, N. Lu, J. Vermeylen, M. J. Kim, Y. Liu, Y. Sun and X. Xia, Nano Lett., 2016, 16, 2812-2817.

7 H. Can and Ö. Metin, Appl. Catal., B, 2012, 125, 304-310.

8 Y. Zhao, Y. Luo, X. Yang, Y. Yang and Q. Song, J. Hazard. Mater., 2017, 332, 124-131.

9 K. Pelzer, O. Vidoni, K. Philippot, B. Chaudret and V. Collière, Adv. Funct. Mater., 2003, 13, 118-126.

10 E. K. Abo-Hamed, T. Pennycook, Y. Vaynzof, C. Toprakcioglu, A. Koutsioubas and O. A. Scherman, Small, 2014, 10, 3145-3152.

11 Y. He, K. Vinodgopal, M. Ashokkumar and F. Grieser, Res. Chem. Intermed., 2006, 32, 709-715.

12 J. Yang, J. Y. Lee, T. Deivaraj and H.-P. Too, J. Colloid Interface Sci., 2004, 271, 308-312.

13 J. D. Hoefelmeyer, K. Niesz, G. A. Somorjai and T. D. Tilley, Nano Lett., 2005, 5, 435-438.

14 A. M. Watson, X. Zhang, R. Alcaraz de la Osa, J. M. Sanz, F. González, F. Moreno, G. Finkelstein, J. Liu and H. O. Everitt, Nano Lett., 2015, 15, 1095-1100.

15 N. Zettsu, J. M. McLellan, B. Wiley, Y. Yin, Z.-Y. Li and Y. Xia, Angew. Chem., Int. Ed., 2006, 45, 1288-1292.

16 R. Das and R. K. Soni, Analyst, 2018, 143, 2310-2322.

17 Y. Zhang, M. E. Grass, J. N. Kuhn, F. Tao, S. E. Habas, W. Huang, P. Yang and G. A. Somorjai, J. Am. Chem. Soc., 2008, 130, 5868-5869.

18 H. Zhang, X. Xia, W. Li, J. Zeng, Y. Dai, D. Yang and Y. Xia, Angew. Chem., Int. Ed., 2010, 49, 5296-5300.

19 S. R. Lee, M. Vara, Z. D. Hood, M. Zhao, K. D. Gilroy, M. Chi and Y. Xia, ChemNanoMat, 2018, 4, 66-70.

20 M. E. Grass, Y. Zhang, D. R. Butcher, J. Y. Park, Y. Li, H. Bluhm, K. M. Bratlie, T. Zhang and G. A. Somorjai, Angew. Chem., Int. Ed., 2008, 47, 8893-8896.

21 J. L. Huang, Z. Li, H. H. Duan, Z. Y. Cheng, Y. D. Li, J. Zhu and R. Yu, J. Am. Chem. Soc., 2017, 139, 575-578.

22 S. Gao, J. Zhang, Y.-F. Zhu and C.-M. Che, New J. Chem., 2000, 24, 739-740.

23 A. Behr, Y. Brunsch and A. Lux, Tetrahedron Lett., 2012, 53, 2680-2683.

24 J. Schulz, A. Roucoux and H. Patin, Chem.-Eur. J., 2000, 6, 618-624.

25 T. D. Ewers, A. K. Sra, B. C. Norris, R. E. Cable, C.-H. Cheng, D. F. Shantz and R. E. Schaak, Chem. Mater., 2005, 17, 514520.

26 M. Harada, D. Abe and Y. Kimura, J. Colloid Interface Sci., 2005, 292, 113-121.

27 J. A. Baeza, L. Calvo, M. A. Gilarranz and J. J. Rodriguez, Chem. Eng. J., 2014, 240, 271-280. 
28 B. Jiang, C. Li, Ö. Dag, H. Abe, T. Takei, T. Imai, M. S. A. Hossain, M. T. Islam, K. Wood, J. Henzie and Y. Yamauchi, Nat. Commun., 2017, 8, 15581.

29 M. Rakap, J. Alloys Compd., 2015, 649, 1025-1030.

30 M. Cui, J. Zhou, Y. Zhao and Q. Song, Sens. Actuators, B, 2017, 243, 203-210.

31 M. Cui, Y. Zhao, C. Wang and Q. Song, Microchim. Acta, 2016, 183, 2047-2053.

32 H. Su, D.-D. Liu, M. Zhao, W.-L. Hu, S.-S. Xue, Q. Cao, X.-Y. Le, L.-N. Ji and Z.-W. Mao, ACS Appl. Mater. Interfaces, 2015, 7, 8233-8242.

33 S. Kundu and H. Liang, J. Colloid Interface Sci., 2011, 354, 597-606.

34 R. Zhang, X. Liu, L. Shi, X. Jin, Y. Dong, K. Li, X. Zhao, Q. Li and Y. Deng, Nanomaterials, 2019, 9, 76.

35 X. Xia, L. Figueroa-Cosme, J. Tao, H.-C. Peng, G. Niu, Y. Zhu and Y. Xia, J. Am. Chem. Soc., 2014, 136, 10878-10881.

36 K. Chakrapani and S. Sampath, Chem. Commun., 2013, 49, 6173-6175.

37 S. R. Ede, U. Nithiyanantham and S. Kundu, Phys. Chem. Chem. Phys., 2014, 16, 22723-22734.

38 T. Wakisaka, K. Kusada, T. Yamamoto, T. Toriyama, S. Matsumura, G. Ibrahima, O. Seo, J. Kim, S. Hiroi, O. Sakata, S. Kawaguchi, Y. Kubota and H. Kitagawa, Chem. Commun., 2020, 56, 372-374.

39 Z. Fereshteh, R. Rojaee and A. Sharifnabi, Superlattices Microstruct., 2016, 98, 267-275.

40 T. Zhao, R. Sun, S. Yu, Z. Zhang, L. Zhou, H. Huang and R. Du, Colloids Surf., A, 2010, 366, 197-202.

41 R. Harpeness, Z. Peng, X. Liu, V. G. Pol, Y. Koltypin and A. Gedanken, J. Colloid Interface Sci., 2005, 287, 678-684.

42 I. Pastoriza-Santos and L. M. Liz-Marzán, Langmuir, 2002, 18, 2888-2894.

43 H. Liu, H. Zhang, J. Wang and J. Wei, Arab. J. Chem., 2020, 13, 1011-1019.

$44 \mathrm{~J}$. L. Hernández-Pinero, M. Terrón-Rebolledo, R. Foroughbakhch, S. Moreno-Limón, M. F. Melendrez, F. Solís-Pomar and E. Pérez-Tijerina, Appl. Nanosci., 2016, 6, 1183-1190.

45 D. Kim, S. Jeong and J. Moon, Nanotechnology, 2006, 17, 4019.

46 H. Kaneko, T. Matsumoto, J. L. C. Huaman, M. Ishijima, K. Suzuki, H. Miyamura and J. Balachandran, Inorg. Chem., 2021, 60, 3025-3036.

47 C. Du, Q. Ao, N. Cao, L. Yang, W. Luo and G. Cheng, Int. J. Hydrogen Energy, 2015, 40, 6180-6187.

48 R. B. N. Baig and R. S. Varma, ACS Sustainable Chem. Eng., 2013, 1, 805-809.

49 C.-M. Ho, W.-Y. Yu and C.-M. Che, Angew. Chem., Int. Ed., 2004, 43, 3303-3307.

50 J. Wang, S. Shen, B. Li, H. Lin and Y. Yuan, Chem. Lett., 2009, 38, 572-573.

51 J. Kang, S. Zhang, Q. Zhang and Y. Wang, Angew. Chem., Int. Ed., 2009, 48, 2565-2568.

52 A. B. Ayusheev, O. P. Taran, I. A. Seryak, O. Y. Podyacheva, C. Descorme, M. Besson, L. S. Kibis, A. I. Boronin,
A. I. Romanenko, Z. R. Ismagilov and V. Parmon, Appl. Catal., B, 2014, 146, 177-185.

53 H.-B. Pan and C. M. Wai, J. Phys. Chem. C, 2009, 113, 1978219788.

54 J. Chen, M. Hu, M. Ming, C. Xu, Y. Wang, Y. Zhang, J. Wu, D. Gao, J. Bi and G. Fan, Int. J. Hydrogen Energy, 2018, 43, 2718-2725.

55 N. Karachi, M. Hosseini, Z. Parsaee and R. Razavi, J. Photochem. Photobiol., A, 2018, 364, 344-354.

56 Y. Motoyama, M. Takasaki, S.-H. Yoon, I. Mochida and H. Nagashima, Org. Lett., 2009, 11, 5042-5045.

57 S. Akbayrak, Y. Tonbul and S. Özkar, Appl. Catal., B, 2016, 198, 162-170.

58 M. J. Jacinto, P. K. Kiyohara, S. H. Masunaga, R. F. Jardim and L. M. Rossi, Appl. Catal., A, 2008, 338, 52-57.

59 M. Rueping, R. M. Koenigs, R. Borrmann, J. Zoller, T. E. Weirich and J. Mayer, Chem. Mater., 2011, 23, 20082010.

60 X. Du, Y. Liu, J. Wang, Y. Cao and K. Fan, Chin. J. Catal., 2013, 34, 993-1001.

61 X. Wu, B. Feng, W. Li, Y. Niu, Y. Yu, S. Lu, C. Zhong, P. Liu, Z. Tian, L. Chen, W. Hu and C. M. Li, Nano Energy, 2019, 62, 117-126.

62 L. Cunci, C. V. Rao, C. Velez, Y. Ishikawa and C. R. Cabrera, Electrocatalysis, 2013, 4, 61-69.

63 H. Wang, M. Ming, M. Hu, C. Xu, Y. Wang, Y. Zhang, D. Gao, J. Bi, G. Fan and J.-S. Hu, ACS Appl. Mater. Interfaces, 2018, 10, 22340-22347.

64 M. Huang, H. Wang, D. He, P. Jiang and Y. Zhang, Chem. Commun., 2019, 55, 3634-3637.

65 G.-Y. Fan, L. Zhang, H.-Y. Fu, M.-L. Yuan, R.-X. Li, H. Chen and X.-J. Li, Catal. Commun., 2010, 11, 451-455.

66 S. He, L. Xie, M. Che, H. C. Chan, L. Yang, Z. Shi, Y. Tang and Q. Gao, J. Mol. Catal. A: Chem., 2016, 425, 248-254.

67 O. Hernández-Cristóbal, G. Díaz and A. Gómez-Cortés, Ind. Eng. Chem. Res., 2014, 53, 10097-10104.

68 C. Kavitha, K. Bramhaiah, N. S. John and S. Aggarwal, $R$. Soc. Open Sci., 2017, 4, 170353.

69 K.-F. Yung and W.-T. Wong, J. Cluster Sci., 2007, 18, 51-65.

70 J. E. Low, A. Foelske-Schmitz, F. Krumeich, M. Wörle, D. Baudouin, F. Rascón and C. Copéret, Dalton Trans., 2013, 42, 12620-12625.

71 T. Molefe, R. P. Forbes and N. J. Coville, Catal. Lett., 2021, 151, 875-887.

72 M. Zahmakıran, S. Akbayrak, T. Kodaira and S. Özkar, Dalton Trans., 2010, 39, 7521-7527.

73 S. Royer and D. Duprez, ChemCatChem, 2011, 3, 24-65.

74 A. K. Santra and D. W. Goodman, Electrochim. Acta, 2002, 47, 3595-3609.

75 T. Engel and G. Ertl, Adv. Catal., 1979, 28, 1-78.

76 J. Assmann, V. Narkhede, L. Khodeir, E. Löffler, O. Hinrichsen, A. Birkner, H. Over and M. Muhler, J. Phys. Chem. B, 2004, 108, 14634-14642.

77 M. Haruta, S. Tsubota, T. Kobayashi, H. Kageyama, M. J. Genet and B. Delmon, J. Catal., 1993, 144, 175-192.

78 E. McCarthy, J. Zahradnik, G. C. Kuczynski and J. J. Carberry, J. Catal., 1975, 39, 29-35. 
79 X. Dupain, R. A. Krul, C. J. Schaverien, M. Makkee and J. A. Moulijn, Appl. Catal., B, 2006, 63, 277-295.

80 Q. Zhang, X. Li, K. Asami, S. Asaoka and K. Fujimoto, Catal. Today, 2005, 104, 30-36.

81 G. Henrici-Olivé and S. Olivé, Angew. Chem., Int. Ed. Engl., 1976, 15, 136-141.

82 Y. Zhang, X. Su, L. Li, H. Qi, C. Yang, W. Liu, X. Pan, X. Liu, X. Yang, Y. Huang and T. Zhang, ACS Catal., 2020, 10, 12967-12975.

83 K. Xiong, Y. Zhang, J. Li and K. Liew, J. Energy Chem., 2013, 22, 560-566.

84 M. Leconte, A. Theolier and J. M. Basset, J. Mol. Catal., 1985, 28, 217-231.

85 A. Fritz and V. Pitchon, Appl. Catal., B, 1997, 13, 1-25.

86 M. Aryafar and F. Zaera, J. Catal., 1998, 175, 316-327.

87 T. W. Root, L. D. Schmidt and G. B. Fisher, Surf. Sci., 1983, 134, 30-45.

88 V. P. Zhdanov and B. Kasemo, Surf. Sci. Rep., 1997, 29, 3190.

89 J. Z. Luo, L. Z. Gao, Y. L. Leung and C. T. Au, Catal. Lett., 2000, 66, 91-97.

90 H. Beyer, K. Chatziapostolou and K. Köhler, Top. Catal., 2009, 52, 1752-1756.

91 E. C. Vermisoglou, G. E. Romanos, G. N. Karanikolos and N. K. Kanellopoulos, J. Hazard. Mater., 2011, 194, 144-155.

92 A. V. Salker and M. S. F. Desai, Appl. Surf. Sci., 2016, 389, 344-353.

93 F. Baudin, P. Da Costa, C. Thomas, S. Calvo, Y. Lendresse, S. Schneider, F. Delacroix, G. Plassat and G. DjégaMariadassou, Top. Catal., 2004, 30/31, 97-101.

94 R. Zhu, Q. Yan, J. He, G. Cao and F. Ouyang, Appl. Catal., A, 2017, 541, 42-49.

95 Y.-W. You, Y. J. Kim, J. H. Lee, M. W. Arshad, S. K. Kim, S. M. Kim, H. Lee, L. T. Thompson and I. Heo, Appl. Catal., B, 2021, 280, 119374.

96 K. Sato, H. Tomonaga, T. Yamamoto, S. Matsumura, N. D. B. Zulkifli, T. Ishimoto, M. Koyama, K. Kusada, H. Kobayashi, H. Kitagawa and K. Nagaoka, Sci. Rep., 2016, 6, 28265.

97 R. M. Esteban, K. Schütte, P. Brandt, D. Marquardt, H. Meyer, F. Beckert, R. Mülhaupt, H. Kölling and C. Janiak, Nano-Struct. Nano-Objects, 2015, 2, 11-18.

98 M. Takasaki, Y. Motoyama, K. Higashi, S.-H. Yoon, I. Mochida and H. Nagashima, Org. Lett., 2008, 10, 16011604.

99 H.-B. Pan and C. M. Wai, J. Phys. Chem. C, 2010, 114, 1136411369.

100 K. H. Park, K. Jang, H. J. Kim and S. U. Son, Angew. Chem., Int. Ed., 2007, 46, 1152-1155.

101 M. Zahmakiran, Dalton Trans., 2012, 41, 12690-12696.

102 J. H. Kwak, L. Kovarik and J. Szanyi, ACS Catal., 2013, 3, 2449-2455.

103 A. Aitbekova, L. Wu, C. J. Wrasman, A. Boubnov, A. S. Hoffman, E. D. Goodman, S. R. Bare and M. Cargnello, J. Am. Chem. Soc., 2018, 140, 13736-13745.

104 Q. Lin, X. Y. Liu, Y. Jiang, Y. Wang, Y. Huang and T. Zhang, Catal. Sci. Technol., 2014, 4, 2058-2063.
105 F. Wang, S. He, H. Chen, B. Wang, L. Zheng, M. Wei, D. G. Evans and X. Duan, J. Am. Chem. Soc., 2016, 138, 6298-6305.

106 S. Li, Y. Xu, Y. Chen, W. Li, L. Lin, M. Li, Y. Deng, X. Wang, B. Ge, C. Yang, S. Yao, J. Xie, Y. Li, X. Liu and D. Ma, Angew. Chem., Int. Ed., 2017, 56, 10761-10765.

107 J. Krajczewski, K. Kołątaj and A. Kudelski, Appl. Surf. Sci., 2016, 388, 624-630.

108 P. Luo, K. Xu, R. Zhang, L. Huang, J. Wang, W. Xing and J. Huang, Catal. Sci. Technol., 2012, 2, 301-304.

109 Y. Lee, S. Jang, C.-W. Cho, J.-S. Bae, S. Park and K. H. Park, J. Nanosci. Nanotechnol., 2013, 13, 7477-7481.

110 A. George, D. Selvan and S. Mandal, ChemistrySelect, 2017, 2, 9718-9721.

111 N. R. Guha, D. Bhattacherjee and P. Das, Tetrahedron Lett., 2014, 55, 2912-2916.

112 Q. Yao, W. Shi, G. Feng, Z.-H. Lu, X. Zhang, D. Tao, D. Kong and X. Chen, J. Power Sources, 2014, 257, 293-299.

113 T. Ayvalı, M. Zahmakıran and S. Özkar, Dalton Trans., 2011, 40, 3584-3591.

114 Q. Yao, Z.-H. Lu, Y. Jia, X. Chen and X. Liu, Int. J. Hydrogen Energy, 2015, 40, 2207-2215.

115 R. Lu, M. Hu, C. Xu, Y. Wang, Y. Zhang, B. Xu, D. Gao, J. Bi and G. Fan, Int. J. Hydrogen Energy, 2018, 43, 7038-7045.

116 W. Luo, W. Cheng, M. Hu, Q. Wang, X. Cheng, Y. Zhang, Y. Wang, D. Gao, J. Bi and G. Fan, ChemSusChem, 2019, 12, 535-541.

117 D. Özhava and S. Özkar, Appl. Catal., B, 2016, 181, 716-726.

118 D. Çelik, S. Karahan, M. Zahmakıran and S. Özkar, Int. J. Hydrogen Energy, 2012, 37, 5143-5151.

119 Ö. Metin, N. A. Alp, S. Akbayrak, A. Biçer, M. S. Gültekin, S. Özkar and U. Bozkaya, Green Chem., 2012, 14, 1488-1492.

120 Y. Zhang, F. Lu, H.-Y. Zhang and J. Zhao, Catal. Lett., 2017, 147, 20-28.

121 D. Chandra, Y. Inoue, M. Sasase, M. Kitano, A. Bhaumik, K. Kamata, H. Hosono and M. Hara, Chem. Sci., 2018, 9, 5949-5956.

122 J. Llop Castelbou, E. Bresó-Femenia, P. Blondeau, B. Chaudret, S. Castillón, C. Claver and C. Godard, ChemCatChem, 2014, 6, 3160-3168.

123 M. Zahmakıran, Y. Román-Leshkov and Y. Zhang, Langmuir, 2012, 28, 60-64.

124 M. Fang and R. A. Sánchez-Delgado, J. Catal., 2014, 311, 357-368.

125 M. Zahmakıran and S. Özkar, Appl. Catal., B, 2009, 89, 104110.

126 Z. Wen, J. Wu and G. Fan, Catalysts, 2020, 10, 1037.

127 X. Li, Y. Yan, Y. Jiang, X. Wu, S. Li, J. Huang, J. Li, Y. Lin, D. Yang and H. Zhang, Nanoscale Adv., 2019, 1, 3941-3947.

128 S. Akbayrak, Y. Tonbul and S. Özkar, Int. J. Hydrogen Energy, 2021, 46, 14259-14269.

129 J. Shen, L. Yang, K. Hu, W. Luo and G. Cheng, Int. J. Hydrogen Energy, 2015, 40, 1062-1070.

130 S. Akbayrak, Y. Tonbul and S. Özkar, ACS Sustainable Chem. Eng., 2020, 8, 4216-4224.

131 Y. Tonbul, S. Akbayrak and S. Özkar, J. Colloid Interface Sci., 2019, 553, 581-587. 
132 E. Taşçı, S. Akbayrak and S. Özkar, Int. J. Hydrogen Energy, 2018, 43, 15124-15134.

133 Y. Tonbul, S. Akbayrak and S. Özkar, Int. J. Hydrogen Energy, 2019, 44, 14164-14174.

134 S. Akbayrak, S. Gençtürk, İ. Morkan and S. Özkar, RSC Adv., 2014, 4, 13742-13748.

135 M. Chandra and Q. Xu, J. Power Sources, 2007, 168, 135-142.

136 G. Fan, Q. Liu, D. Tang, X. Li, J. Bi and D. Gao, Int. J. Hydrogen Energy, 2016, 41, 1542-1549.

137 S. Akbayrak and S. Özkar, ACS Appl. Mater. Interfaces, 2012, 4, 6302-6310.

138 K. Yang, L. Zhou, G. Yu, X. Xiong, M. Ye, Y. Li, D. Lu, Y. Pan, M. Chen, L. Zhang, D. Gao, Z. Wang, H. Liu and Q. Xia, Int. J. Hydrogen Energy, 2016, 41, 6300-6309.

139 M. Zahmakiran, Mater. Sci. Eng. B, 2012, 177, 606-613.

140 S. Akbayrak, S. Tanyıldızı, İ. Morkan and S. Özkar, Int. J. Hydrogen Energy, 2014, 39, 9628-9637.

141 J. R. Deka, D. Saikia, K.-S. Hsia, H.-M. Kao, Y.-C. Yang and C.-S. Chen, Catalysts, 2020, 10, 267.

142 H. Liang, G. Chen, S. Desinan, R. Rosei, F. Rosei and D. Ma, Int. J. Hydrogen Energy, 2012, 37, 17921-17927.

143 Y. Tonbul, S. Akbayrak and S. Özkar, J. Colloid Interface Sci., 2018, 513, 287-294.
144 E. B. Kalkan, S. Akbayrak and S. Özkar, Mol. Catal., 2017, 430, 29-35.

145 L. Wen, J. Su, X. Wu, P. Cai, W. Luo and G. Cheng, Int. J. Hydrogen Energy, 2014, 39, 17129-17135.

146 S. Akbayrak, Y. Tonbul and S. Özkar, Dalton Trans., 2016, 45, 10969-10978.

147 S. Akbayrak, P. Erdek and S. Özkar, Appl. Catal., B, 2013, 142-143, 187-195.

148 L. Wen, Z. Zheng, W. Luo, P. Cai and G.-Z. Cheng, Chin. Chem. Lett., 2015, 26, 1345-1350.

149 M. Sait Izgi, M. Ş. Ece, H. Ç. Kazici, Ö. Şahin and E. Onat, Int. J. Hydrogen Energy, 2020, 45, 30415-30430.

150 S. Basu, A. Brockman, P. Gagare, Y. Zheng, P. V. Ramachandran, W. N. Delgass and J. P. Gore, J. Power Sources, 2009, 188, 238-243.

151 N. Cao, W. Luo and G. Cheng, Int. J. Hydrogen Energy, 2013, 38, 11964-11972.

152 G. P. Rachiero, U. B. Demirci and P. Miele, Catal. Today, 2011, 170, 85-92.

153 Y.-T. Li, S.-H. Zhang, G.-P. Zheng, P. Liu, Z.-K. Peng and X.-C. Zheng, Appl. Catal., A, 2020, 595, 117511.

154 L. Fu and L. Cai, Int. J. Hydrogen Energy, 2021, 46, 1074910762. 